\title{
The pathology of human aortic valve homografts
}

\author{
J U D I T H C. S M I T H ${ }^{1}$ \\ From Auckland, New Zealand
}

\begin{abstract}
Beta-propiolactone sterilized, freeze-dried aortic valve homografts offer a dead framework which is accepted by the host and is capable of immediate and full function. The survival time of such grafts as fully functional units may be limited by physical and chemical alterations produced in the tissues by sterilization and freeze-drying. The organizing reaction of the host in covering the grafts or using them as a scaffolding may also be affected by these processes. It is possible that better long-term results may be achieved by using fresh grafts. There is no difference in host cellular response to fresh and sterilized and/or freeze-dried grafts. There is a possibility that heterogeneous reactions to polypeptides in the graft may occur in some individuals. Organization and covering of the graft by host tissue occurs from host tissues contiguous to the graft. Cells circulating in the bloodstream play no part in this by seeding on the surface. Thrombosis, in the absence of infection, is a rare complication. (Anticoagulants were not used in these patients.) Calcification occurs as only a late complication in persisting 'dead' tissue. Unsuspected, and often extensive, myocardial ischaemia occurs frequently under bypass conditions with coronary artery perfusion and substantially contributes to immediate post-operative mortality and morbidity.
\end{abstract}

Replacement of the aortic valve by a homologous orthotopic graft has been established as an acceptable treatment for aortic valve disease in man by Ross (1962) and Barratt-Boyes (1964) using fresh or sterilized and freeze-dried donor valves. The pioneer work in man and the early and continuing work in animals was undertaken using fresh material (Lam, Aram, and Munnell, 1952; Murray, 1956, 1960 ; Beall, Morris, Cooley, and De Bakey, 1961; Kerwin, Lenkei, and Wilson, 1962 ; Heimbecker, Baird, Lajos, Varga, and Greenwood, 1962 ; Robicsek, Sanger, Taylor, and Robicsek, 1962 ; Berghuis, Rastelli, Van Vliet, Titus, Swan, and Ellis, 1964; Van Vliet, Titus, Berghuis, and Ellis, 1965 ; and McKenzie, Titus, Rastelli, Pappas, and Ellis, 1966). Survival of a fresh aortic valve transplant has been reported at over eight years by Bigelow, Yao, Aldridge, Heimbecker, and Murray (1964). The use of sterilized, freeze-dried material has been reported by Harp, Olson, and McGoon (1963) in calves and by Davies, Lessof, Roberts, and Ross (1965) in man. In a detailed report on work in dogs, Lower, Pillsbury, Angell, and Kosek (1966) have included a histological description of the appearances of five human grafts, one of which had been

${ }^{1}$ Present address : Section of Experimental and Anatomic Pathology. Mayo Graduate School of Medicine. Rochester, Minnesota 55901. U.S.A. present for two years. Hudson (1966) has also described some aspects of the morbid anatomy of 20 grafts. The cases described in both these latter papers had been patients of Mr. D. N. Ross. Foster, Collins, Jacobs, and Scott (1965) report a nine-year survival of segments of aorta (not including the aortic valve) which had been sterilized in ethylene oxide and freeze-dried.

Now that cardiac valve replacement is being so widely undertaken there is, as Bigelow et al. (1964) point out, a responsibility to find out which type of valve replacement is likely to give the most satisfactory long-term results. This report on a series of homotransplanted valves, the majority of which have been sterilized and freezedried, may be applicable to this problem.

\section{MATERIAL AND METHODS}

Fifty-three orthotopically homotransplanted human aortic valves have been examined at periods ranging from one day to two years five months after insertion. Twenty-seven were in place for a month or less, three for one to three months, 12 for three to 12 months, and 11 for over a year. Of these 11 , six were in place for two years and over. All were from patients of Mr. B. G. Barratt-Boyes.

The early grafts were taken from donors less than 45 years old and within 15 hours of death. Later, the age limit was increased to 65 years and over for 
satisfactory valves, and a time lapse of 48 hours post mortem was permitted. However, most valves were removed within 24 hours of death. The ages of the donors ranged from 12 to 66 years. Seventeen were under 40 years of age, 15 between 40 and 50, 15 were in the next decade, and four were more than 60 years old. The ages of two were not recorded. It was a policy to match the ages of the graft and the recipient in a general way and, in particular, the clder grafts were inserted only into patients of a comparable age. Most of the grafts came from local hospital and city mortuaries, but six were removed in distant cities and air-freighted to this centre under refrigeration in saline containing penicillin and streptomycin. In the early stages of this work the grafts were removed under aseptic conditions by cardiothoracic surgeons. Later, removal was carried out by pathologists in the course of routine necropsy work. These unsterile valves were sterilized by $1 \%$ betapropiolactone (Rains, Crawford, Sharpe, Shrewsbury, and Barson, 1956). All grafts were kept in nutrient mədium similar to that described by Gross, Bill, and Peirce (1949) with 5,C00 units of penicillin and $0.2 \mathrm{ml}$. of $50 \%$ streptomycin sulphate and stored at $4^{\circ} \mathrm{C}$. until bacteriological tests had confirmed sterility. Some were used directly from this solution; others, a ter confirmation of sterility at the end of a week, were then freeze-dried. The latter valves were reconstituted in distilled water for $\mathbf{3 0}$ minutes and then in isotonic saline in the operating theatre immediately before use.

Of the 53 valves, 11 were removed under aseptic conditions and five of these were used directly from nutrient mədium after 2, 3, 11, 14, and 24 days' storage. The other six were freeze-dried. The remaining 42 valves were sterilized by $1 \%$ beta-propiolactone and 10 of these were stored and used from nutrient medium. The other 32 were freeze-dried, and of these three were sterilized twice and two were freeze-dried twice. The treatment of individual valves examined at and after three months' implantation is included in Table I.

Valve replacement was carried out by the cardiothoracic surgical unit. The grafts were implanted in the subcoronary position very slightly higher than the level of the patient's own valve (Fig. 1). It was often impossible to remove all the calcification in the region of the host valve ring. The surgical technique and clinical material and experience have been reported by Barratt-Boyes $(1964 ; 1965)$.

The 53 specimens reported here were derived from 50 patients, three patients having had two successive grafts each. The transplants were examined in situ in the intact heart after death in $\mathbf{4 2}$ cases and following surgical excision in the other 11. Each of the 42 deaths had a full post-mortem examination. Ten of these necropsies were performed by pathologists in other centres, and the intact hearts were sent to this hospital for examination together with a report on the post-mortem findings.

Fixation was by $10 \%$ formalin. In the earlier specimens cotton-wool pledgets were used to position
TA B LE I

TREATMENT AND FATE OF DONOR VALVES EXAMINED AT AND AFTER 3 MONTHS' IMPLANTATION

\begin{tabular}{|c|c|c|c|c|c|c|}
\hline Patient & $\underset{\text { (mths) }}{\text { Duration }}$ & $\begin{array}{c}\text { Steriliza- } \\
\text { tion }\end{array}$ & $\begin{array}{c}\text { Freeze- } \\
\text { dried }\end{array}$ & $\begin{array}{c}\text { Duration } \\
\text { of } \\
\text { Storage }\end{array}$ & $\begin{array}{l}\text { Rup- } \\
\text { ture }\end{array}$ & $\begin{array}{l}\text { Degen- } \\
\text { eration }\end{array}$ \\
\hline $\begin{array}{l}\text { R.E.W. } \\
\text { R.B. } \\
\text { J.S.R. } \\
\text { A.E.A. } \\
\text { E.T. } \\
\text { L.Q. } \\
\text { L.N. } \\
\text { C.W. } \\
\text { R.N. } \\
\text { R.McK. } \\
\text { P.H. } \\
\text { J.D.R. } \\
\text { J.L. } \\
\text { P.McM. } \\
\text { B.K. } \\
\text { A.M. } \\
\text { P.M. } \\
\text { E.M. } \\
\text { I.McI. } \\
\text { J.N. } \\
\text { C.C. } \\
\text { N.B. } \\
\text { P.T. } \\
\text { T.C. }\end{array}$ & $\begin{array}{l}3 \\
3 \frac{1}{2} \\
3 \frac{1}{2} \\
4 \frac{1}{1} \\
4 \frac{1}{2} \\
4 \frac{1}{2} \\
4 \frac{1}{2} \\
5 \\
6 \\
7 \\
8 \\
9 \\
11 \\
13 \\
15 \\
17 \\
17 \\
22 \\
24 \\
24 \\
24 \\
25 \\
27 \\
29\end{array}$ & $\begin{array}{l}\text { B.P1. } \times 2 \\
\text { B.F1. } \times 2 \\
\text { B.Pl. } \\
\text { B.P1. } \\
\text { B.F1. } \\
\text { B.F1. } \\
\text { B.Pl. } \\
\text { B.Pl. } \\
\text { B.Pl. } \\
\text { B.Pl. } \\
\text { B.Pl. } \\
\text { B.F1. } \\
\text { B.P1. } \times 2 \\
\text { B.P1. } \\
\text { B.P1. } \\
\text { B.F1. } \\
\text { B.P1. }\end{array}$ & $\begin{array}{l}+ \\
+ \\
+ \\
+ \\
+ \\
+ \\
+ \\
\dot{x} 2 \\
+ \\
\\
+ \\
+ \\
+ \\
+ \\
+ \\
+ \\
+ \\
+ \\
+ \\
+\end{array}$ & $\begin{array}{r}4 \text { weeks } \\
11 \text { days } \\
4 \text { weeks } \\
11 \text { days } \\
6 \text { weeks } \\
10 \text { weeks } \\
4 \text { weeks } \\
16 \text { weeks } \\
11 \text { weeks } \\
31 \text { weeks } \\
3 \text { weeks } \\
3 \text { days } \\
4 \text { weeks } \\
\text { Unknown } \\
24 \text { days } \\
11 \text { days } \\
13 \text { days } \\
1 \text { day } \\
5 \text { weeks } \\
2 \text { weeks } \\
6 \text { weeks } \\
6 \text { weeks } \\
2 \text { weeks } \\
7 \text { weeks }\end{array}$ & $\begin{array}{l}+ \\
+ \\
+ \\
+ \\
+\end{array}$ & $\div$ \\
\hline
\end{tabular}

B.PI. $=$ Sterilized with beta-propiolactore

the valve leaflets and to distend the heart chambers. Later, and in most of the long-term grafts, because the presence of an endothelial covering on the grafts was doubted, contact with the graft surfaces was avoided. Sections were cut in the longitudinal plane to include host and graft aortic sinus walls, annuli, and aortic roots in continuity with the graft cusp. Part of the anterior leaflet of the host mitral valve was included in sections of the graft non-coronary cusp (Figs 1 and 9). In each case a minimum of two cusps was sectioned. Usually only one block was taken from each cusp, but on occasions two or more blocks were removed from a single leaflet, this being routine with ruptured cusps. Residual host calcification was often present and required decalcification in Clark's solution (equal parts of $45 \%$ formic acid and $6.8 \%$ sodium formate). Paraffin sections were used. Frozen sections were made for fat stains in some instances. From each block paired sections, one stained with haematoxylin and eosin (H. and E.) and one stained with Verhoeff's elastic stain and van Gieson counterstaining (E.V.G.), were taken at three levels as a basic routine. Stains for fibrin (Weigert's method), calcium (Von Kossa), organisms (Gram's stain, P.A.S.), and fat (Sudan III and IV and Oil Red O) were also used. Between 18 and 36 sections were examined from each graft.

\section{RESULTS}

Of the 42 deaths, 26 occurred in hospital during the first two and a half months following operation. In this group seven cases had had multivalve surgery and four of these were included in the nine patients who died within 24 hours of operation. A further 10 


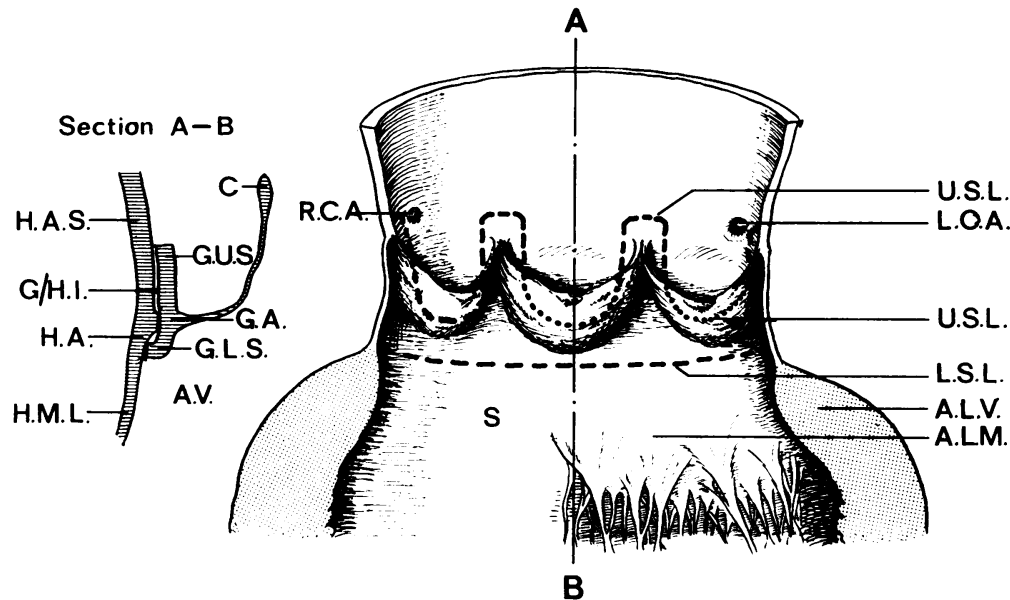

FIG. 1. Diagrammatic representation of a grafted valve in place. (Right) The aorta has been opened longitudinally at the commissure between the right and left coronary cusps of the valve. The upper and lower limits of the grafts are indicated. The coronary arteries are clear of the graft area. The plane in which the histological sections were taken is indicated $(A-B)$. R.C.A.= right coronary artery; L.C.A.= left coronary artery; U.S.L.= upper suture line; L.S.L.=lower suture line; A.L.V.=anterior wall of left ventricle; A.L.M.=anterior leaflet of mitral valve; $S=$ septum. (Left) Diagrammatic representation of a section cut from the non-coronary cusp in the plane of $A-B$. H.A.S.=host aortic sinus wall; G.U.S.=graft upper sleeve (aortic sinus wall); G.A.=graft annulus; H.A.=host annulus; G./H.I. = graft / host interface; G.L.S. = graft lower sleeve (aortic root); A.V. $=$ aortic vestibule; H.M.L. $=$ host anterior leaflet of mitral valve; C.=graft cusp.

patients died in the first week, including two other multivalve cases. Five cases died between one and four weeks after surgery. There was one death at six weeks and one at two and a half months after operation.

Massive recent subendocardial necrosis of the left ventricle, usually involving the inner two-thirds of the whole of the wall, caused death in eight patients who died in the first week and was probably the cause of death in one other in whom the histological evidence was equivocal. In all, the histological appearances were in keeping with infarction at the time of operation. No thrombotic, embolic, or atheromatous occlusions of the coronary arteries were found, but in four cases there were recent dissections of one or other coronary artery (Fig. 2). One of these was an extension of a dissection originating at the cannulation site in the right femoral artery and spiralling the length of the aorta to involve the left coronary artery. At the site of cannulation in the femoral artery there was a large atheromatous plaque with atrophy of the underlying media. This dissection lay outside the external elastic lamina and continued in this plane for the whole of its course. There was no splitting of the media and no medionecrosis of the aorta. In the other three cases the plane of cleavage lay immediately inside the external elastic lamina but not at the junction of the middle and outer thirds of the media (Fig. 2b). No medial disease was present. Two cases had moderate atheroma with narrowing of the lumina of the vessels by one-third of their diameter.

Infection caused five hospital deaths, four from endocarditis of the graft and one from septicaemia. One graft endocarditis (15 days) was thought to have resulted from insertion of an already infected valve which had been reconstituted but not used six days earlier and was then kept in nutrient medium. Th infecting organism was a fungus of candida type. Two cases (seven days and one month) were caused by Klebsiella pneumoniae and one (six weeks) by coagulase-positive Staphylococcus aureus. One cass was due to by-pass machine breakdown (one month) The septicaemia (two days) was caused by Proteus mirabilis.

There were four respiratory deaths, three occurring within the first six days, and two of these followe inhalation of blood from acute gastric erosions. Acute renal failure caused by multiple renal infarct after periods of anoxia in the immediate postoperative phase was responsible for two deaths (fiv 


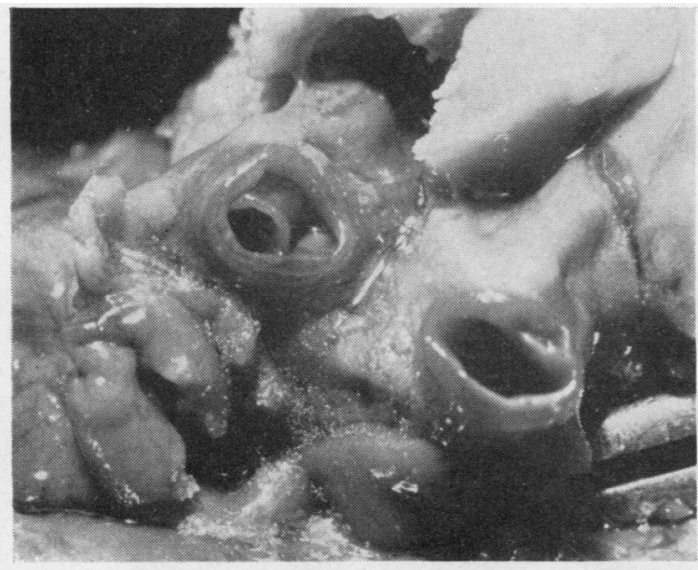

FIG. 2. (a) Dissection of the left coronary artery. The vessel has been transversely sectioned within $5 \mathrm{~mm}$. of its origin. The crump'ed inner layer is seen partly obstructing the lumen of the segment on the left. (b) Dissection of the right coronary artery. The plane of cleavage is immediately inside the external elastic lamina. Blood clot lies in the space between the two layers. There is some atheroma of the intima. The patient was aged 34 years and died within 24 hours of operation with massive sub?ndocardial necrosis. $H$. and $E . \times 45$.

(a)

(b)

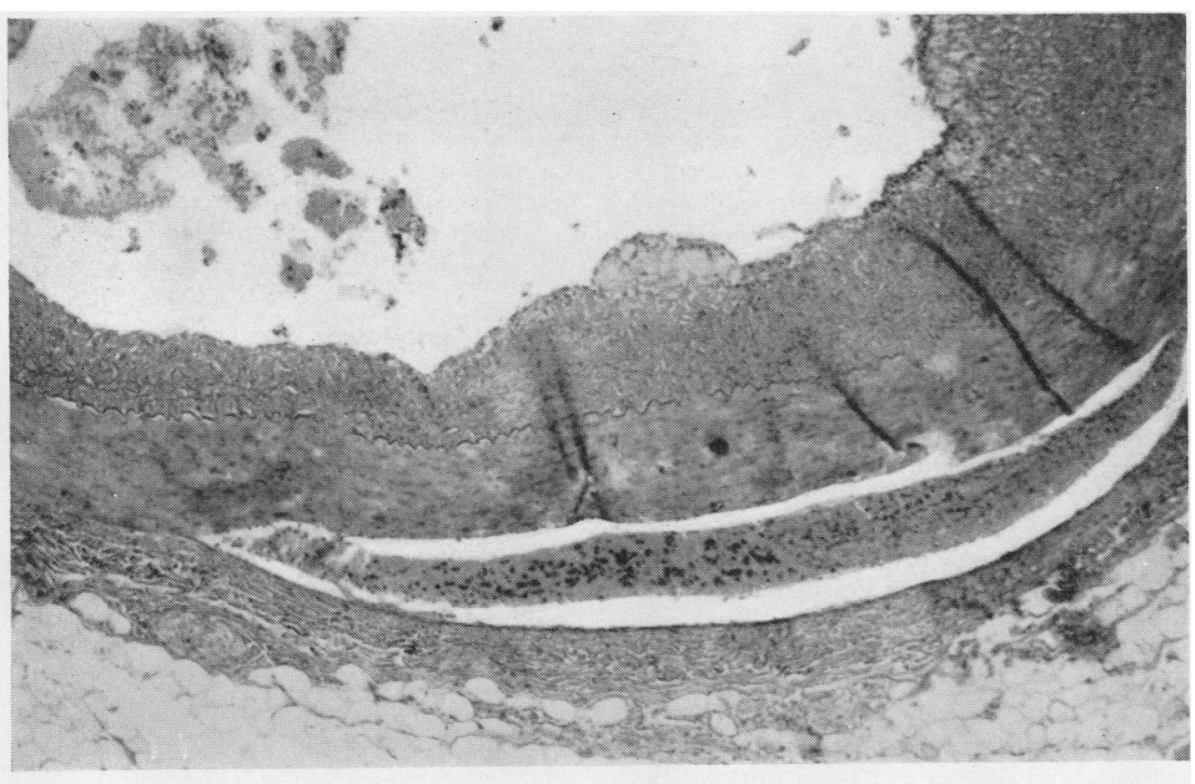

and six days). One patient died because there was an inadequate supply of blood for replacement during a massive haemorrhage. This patient had had a complete repair of tetralogy of Fallot two months earlier. The only finding in one case (seven days) was a haematoma of the interatrial septum which probably caused an arrhythmia. One patient (eight days) died with paralytic ileus, thrombi on the endocardium over the right atrial incision and left ventriculotomy wound, and embolism and infarction of the right lung and infarction of both kidneys and spleen. One death (13 days) followed a period of poor respiratory and renal function in a patient who had had a StarrEdwards prosthesis replacement of the mitral valve.
A lightly adherent ring of thrombus partially covered the atrial aspect of the metal ring. The myocardium showed scattered focal necrosis. Small foci of recent necrosis in the wall of the left ventricle and base of the interventricular septum were the only findings in one case (two days). The patient who died at two and a half months had poorly controlled diabetes mellitus, infection and dehiscence of the sternal wound, and a right-sided empyema.

Six of these patients who died in hospital had appreciable widespread focal scarring of the myocardium associated with fibrocellular or fibroelastic, eccentric, obstructive, intimal lesions of mural arteries (Fig. 3). Eight had widespread acute focal necrosis 


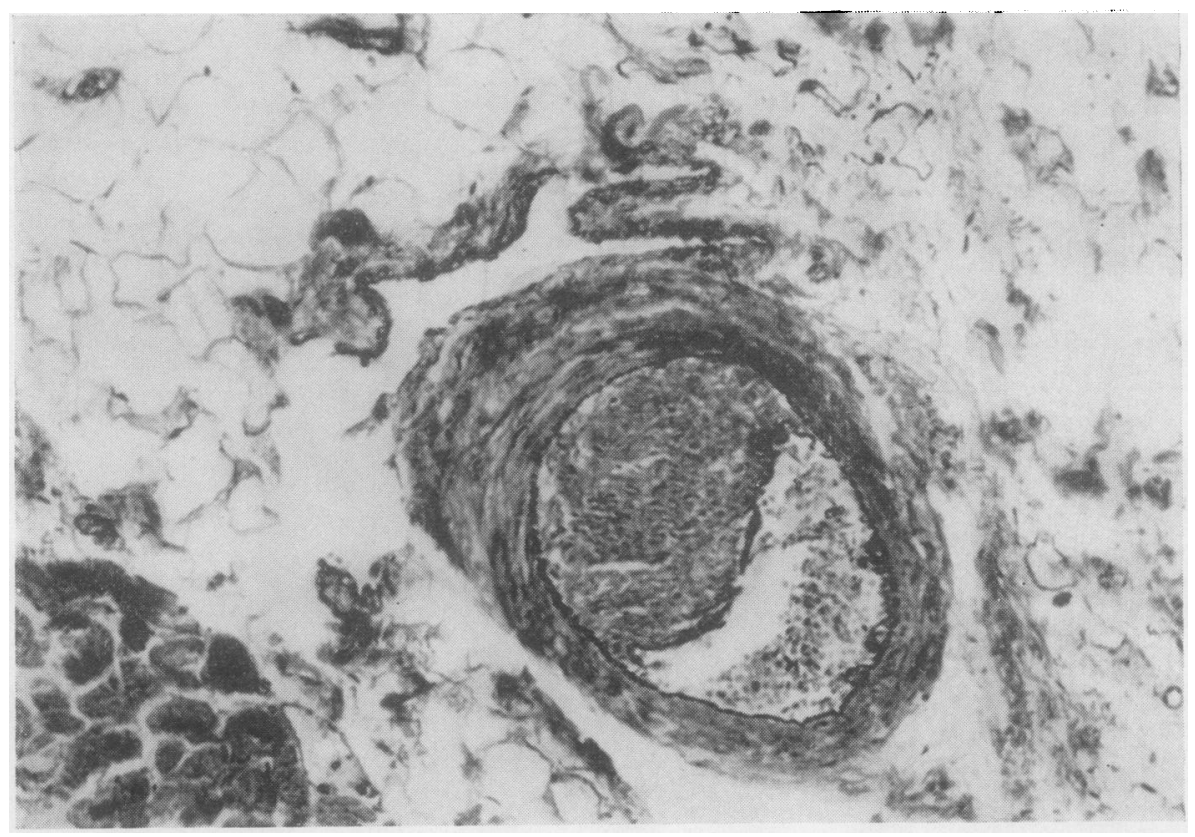

FIG. 3. Small myocardial artery obstructed by an eccentric fibrocellular intimal plaque. A small focus of fibrosis lay in the immediately adjacent ventricular muscle. This is from the same patient as Fig. 2 b. E.V.G. $\times 125$.

of the left ventricle and three had recent anterior or posterior myocardial infarctions.

The 16 late deaths occurred between three months and two years five months after surgery. Seven occurred between three and five months and one each at $6,7,11,13,15,22,24,25,27$, and 29 months. Myocardial disease was responsible for six deaths, three of which had both recent and old healed infarcts (three and a half to four and a half months). One had a healed infarct and extensive focal myocardial scarring and a history of intermittent heart block (four and a half months). The other two patients (15 and 29 months) had enormously dilated hearts $(1,012$ and $1,000 \mathrm{~g}$. respectively) showing severe interstitial fibrosis and widespread focal fibrosis. Both had severe, intractable congestive heart failure thought to be caused by myocardial disease, and this was verified by angiotensin infusion in one patient who had died at 29 months (Barratt-Boyes, Lowe, Cole, and Kelly, 1965; Kelly, 1966). Three sudden deaths in apparently well persons had no apparent cause. All had appreciable myocardial fibrosis. One of these at four and a half months had pulmonary oedema and widespread focal myocardial fibrosis, one at five months an old postero-septal infarct and extreme narrowing of the left coronary artery, and one at 22 months had subendocardial fibrosis with several more recent scars and one focus of fresh necrosis in the base of the interventricular septum. Six of the late deaths had appreciable focal myocardial fibrosis associated with obstructive lesions of the mural arteries.

Aortic incompetence, the result of graft rupture, caused two deaths (four and a half and seven months, Fig. 4). Suicide was the cause of death in the six-o month patient, but this one also had a rupture of the belly of the right coronary cusp which had been ${ }_{\sigma}^{\times}$ suspected before death.

Cerebellar infarction was found in a hypertensive patient who died 11 months after grafting; bacterialo endocarditis of the mitral valve in the patient who died at 13 months; and acute bronchitis and meta-윽 static adenocarcinoma from a primary site in the $D$ prostate in the death at two years (C. C.). The deatho at 27 months followed severe heart failure with multiple organizing pulmonary infarcts and pulmonaryo emboli, mural thrombus on a healed posterior myo- $N$ cardial infarct, and abacterial thrombi on the aortic N surfaces of the graft cusps. There was an incidental $\omega$ adenocarcinoma of the prostate.

The operative specimens were removed because ofo aortic incompetence. In six patients this was caused $\frac{}{\Phi}$ by separation of the graft sleeve from the host aorta? ( 7,10 , and 14 days, 3,8 , and 9 months). This was 0 thought to be due to insertion of too small a graftō in four patients. In the early operative experience it was not fully appreciated that ample redundancy of leaflet tissue was necessary for full competence. Two ( 7 and 16 days) were successive transplants in a patient in whom an area of necrosis was found in the 

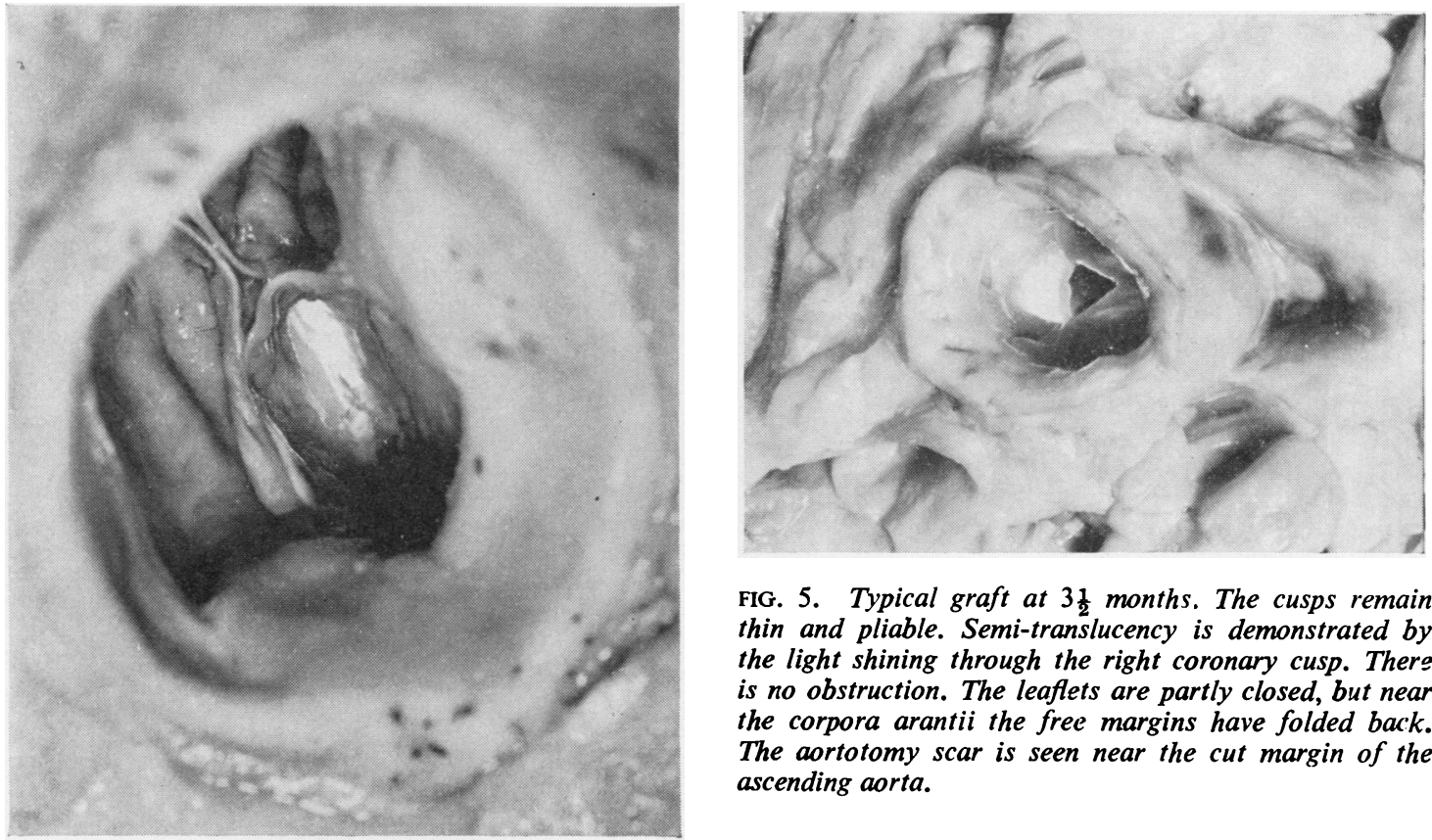

FIG. 5. Typical graft at $3 \frac{1}{2}$ months. The cusps remain thin and pliable. Semi-translucency is demonstrated by the light shining through the right coronary cusp. There is no obstruction. The leaflets are partly closed, but near the corpora arantii the free margins have folded back. The aortotomy scar is seen near the cut margin of the ascending aorta.

FIG. 4. Valve rupture. A ragged-edged hole replaces most of the belly of the left coronary cusp ( 7 months).

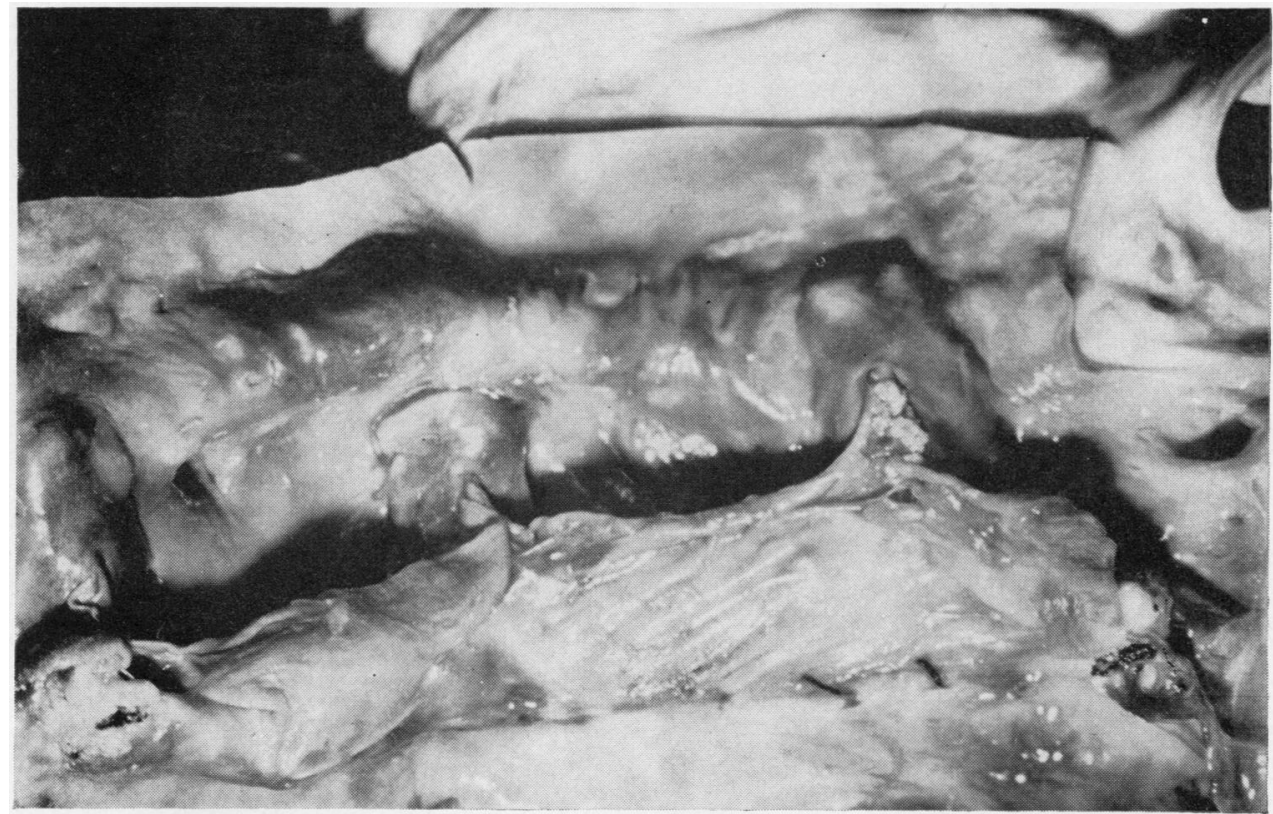

FIG. 6. Graft at 2 years 5 months. The cusps are slightly opaque but are not thickened. This patient had large vegetations on a fibrosed mitral valve, and two small fibrinous verrucae are seen on the commissure of the left coronary cusp. No bacteria were seen. Two stitches are visible at the lower suture line. 
aorta at the site of grafting. In the other five surgically excised specimens the graft had ruptured. Two had been present for 17 months, two for 24 months, and one for 25 months. The ruptures were always found at one or other of two sites and occurred either in the belly of a cusp close to the line of attachment or at the free margin very close to a commissure. Of the 17-month grafts, one (A. M.) had a rupture of the belly of the left coronary cusp and a tear of the free margin of the non-coronary cusp adjacent to a commissure; the other (P. M.) had tears at both commissures of the non-coronary cusp. Both the 24-month grafts had marginal tears. In I. McI. this involved the right coronary cusp ; in J. N. the left coronary cusp. The 25 -month specimen had an extensive rupture of the belly of the non-coronary cusp. In no case was any thrombus, vegetation, or calcification related to the ruptures.

GRAFT DETAIL For scme days after insertion the raw upper suture line and the sutures showed no change. In the latter half of the first month a thin filmy covering was apparent at both suture lines and on the exposed suture material. At three months both suture lines were largely obliterated by an opaque sheath, and the upper and lower limits of the graft were discernible only on close inspection. Definition of these points became increasingly more difficult in older grafts. In no graft did the sheaths become thick enough to cause obstruction. The cusps were slightly thicker than normal in the first weeks but remained soft and pliable (Fig. 5). They lost some of their semi-translucency, and this appearance persisted (Fig. 6). Only in the group of late ruptures did the leaflets appear thinner than normal. From three months onwards there was usually a slight thickening of the

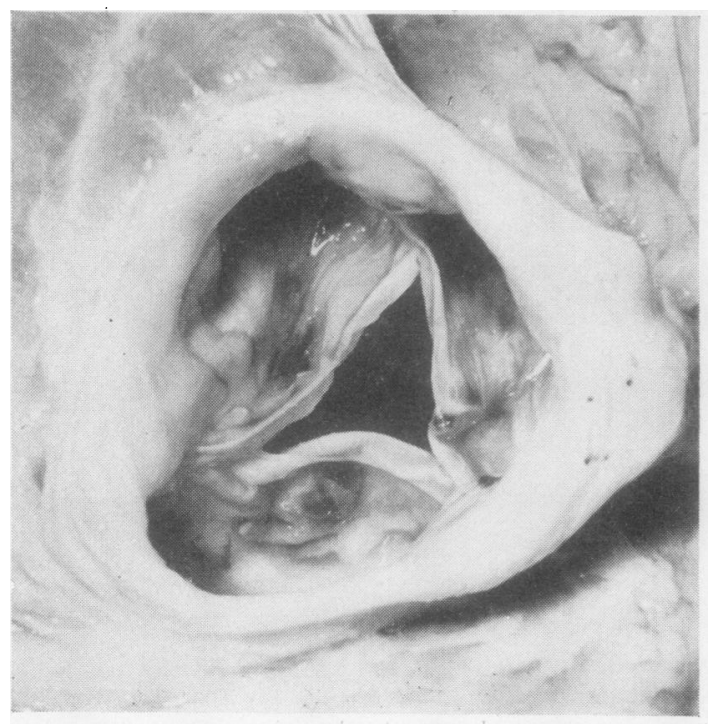

(a) cusps at the line of attachment, but only one valve (two years three months) showed appreciable irregular thickening of the leaflets (Fig. 7). This was caused by thrombosis in a patient with widespread pulmonary infarction, pulmonary emboli, and thrombi on the mural endocardium of the left ventricle overlying an old scar.

Histclogical examination showed that, in general, the grafts retained their normal architecture (Figs 8 and 9), but that there were alterations in detailed structure, changes more evident in the older grafts. The ruptured specimens showed marked alterations in siructure.

Of the grafts examined within a month of grafting only one (two days) had a high complement of donor fibroblasts in the aortic sleeve. This valve had been removed aseptically and inserted after two days in nutrient medium. Two of the unsterilized, freeze-dried valves examined at one day had appreciable numbers of nuclei remaining, but all were degenerate. With the exception of the patient who died at one month with endocarditis, all the other grafts in this group had been sterilized and all but nine had been freeze-dried No donor nuclei were seen in these grafts. In all grafts the cusps were acellular.

Valves from older donors showed aging changes similar to those described by Sell and Scully (1965). A common finding was a fibro-elastic 'spur' on th. ventricular surface at the line of closure (Fig. 24) These lesions were similar to some described by Magarey (1949) on the mitral valve and were distinguishable from changes associated with transplantation.

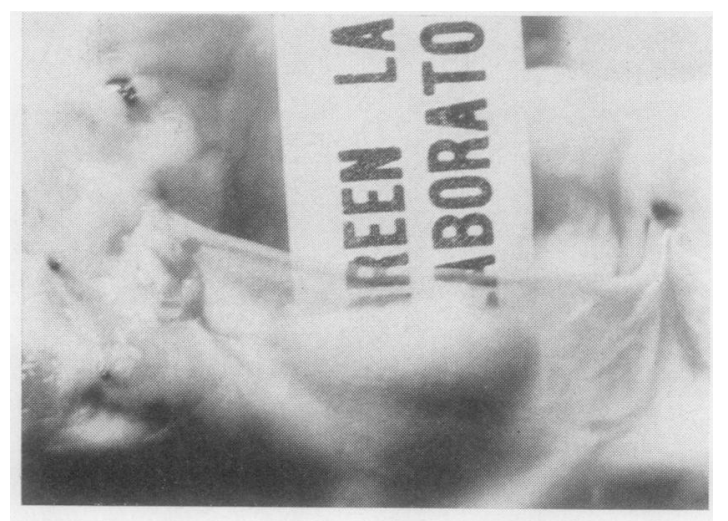

(b)

FIG. 7. (a) Graft at 27 months. Shows the irregular thickening of the cusps caused by thrombi on the aortic surfaces. $A$ nodular lesion is present on the right coronary cusp. (b) Right coronary cusp at 27 months. The patchy natur of the lesions is obvious. Elsewhere the cusp is thin and semi-translucent. No bacteria were present. This patien had pulmonary infarcts and emboli, and mural thrombus on the endocardium overlying an old posterior scar in the left ventricle. 


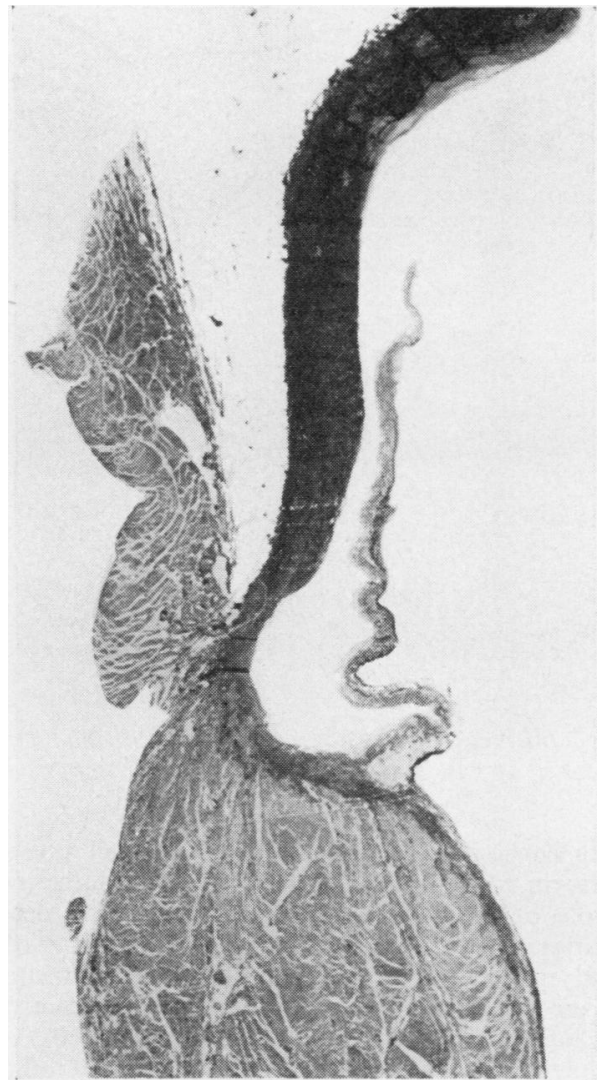

FIG. 8 .

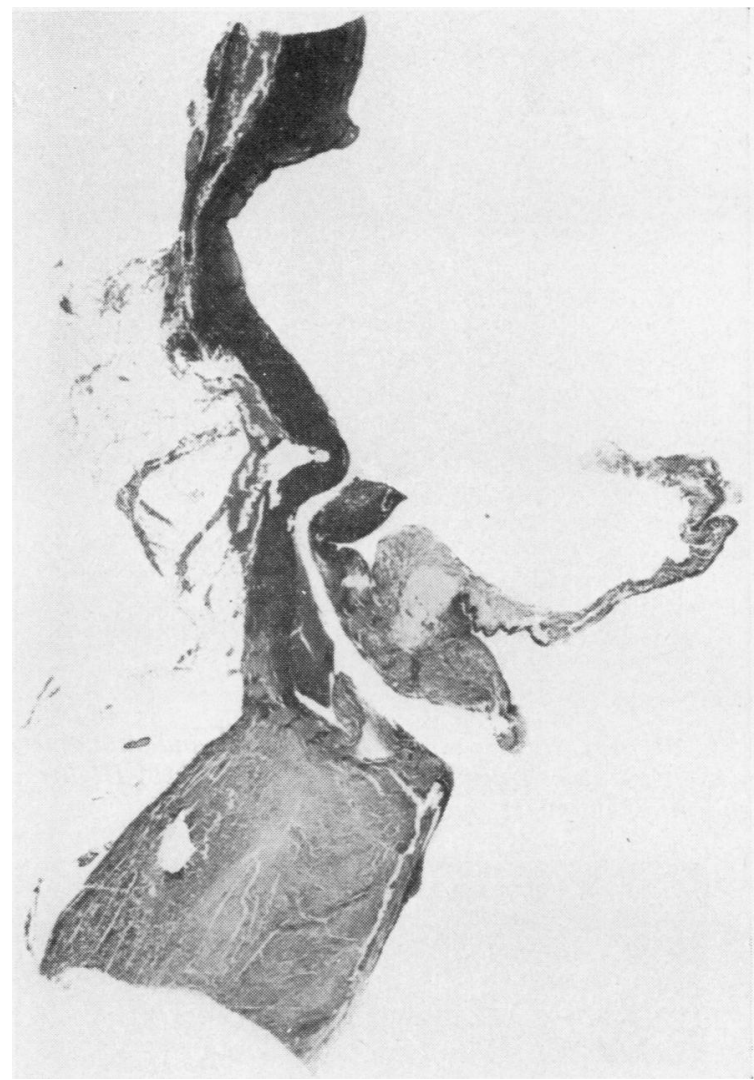

FIG. 9

FIG. 8. Longitudinal section through the left coronary cusp of a control valve aged 50 years. E.V.G. $\times 2$.

FIG. 9. Longitudinal section through the left coronary cusp at one day. Separation of graft and host rings is a processing effect. This shows the tissue included in the grafts; above, aortic elastic tissue in the upper part of the graft sleeve lining the sinus of Valsalva; centrally, the annulus and cusp; below, cardiac muscle of donor left ventricle. This graft had been freeze-dried and reconstituted. The cusp is oedematous. E.V.G. $\times 1 \cdot 5$.

During the first week after grafting the cusps were oedematous, and this was more marked in grafts which had been freeze-dried and reconstituted. The fibrosa of these leaflets had a 'honeycomb' appearance.

Occasional thin discrete deposits of fibrin were seen on cusp surfaces and on the sleeves, but were extensive in only two grafts, neither of which had been freeze-dried. On the surfaces of and within the superficial layers of both sides of the cusps small linear groups of large mononuclear cells and a few neutrophils were found (Fig. 10). The larger cells were rather flattened with their long axes parallel to the cusp surface. Similar small groups of cells were found on and just under the cusp surfaces throughout the series. They were often associated with thin deposits of fibrin. At two days an acute inflammatory exudate was present in the host about the suture material and a few scattered macrophages and neutrophils were seen in the graft sleeve in direct relationship to this exudate. At the end of the first week small thrombi were seen at the upper and lower suture lines. These increased in size in older grafts, and at two weeks a thin film of fibrin extended from them on to the intimal surface of the graft sleeve. At this time young granulation tissue was found in the deepest layer of the clots at the suture lines.

The three grafts between two and six weeks were infected and the cusps were distorted by vegetations. The sleeves were not involved in the specimens at four and six weeks and organizing granulation tissue was present in the clot at the suture lines. A few thin strands of fibrous tissue extended from these foci into the fibrin deposits on both upper and lower portions of the graft sleeves (Fig. 11). Scattered large 


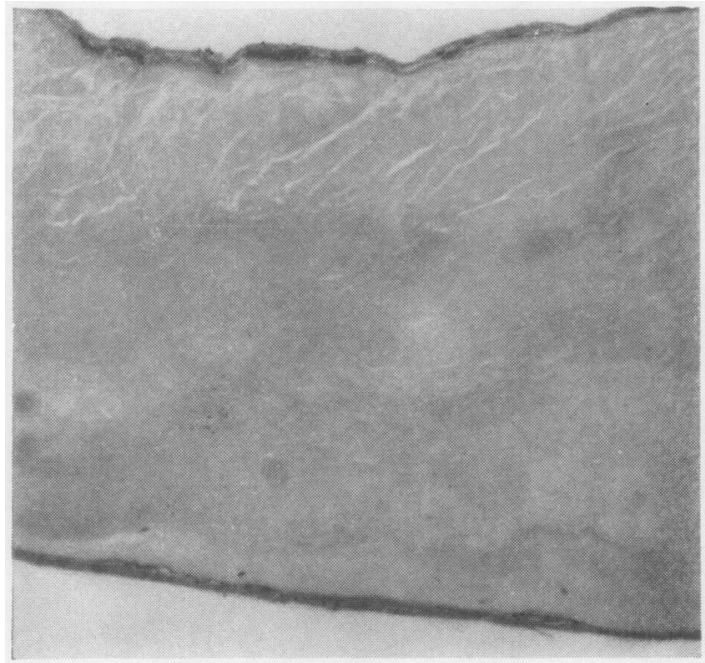

(a)

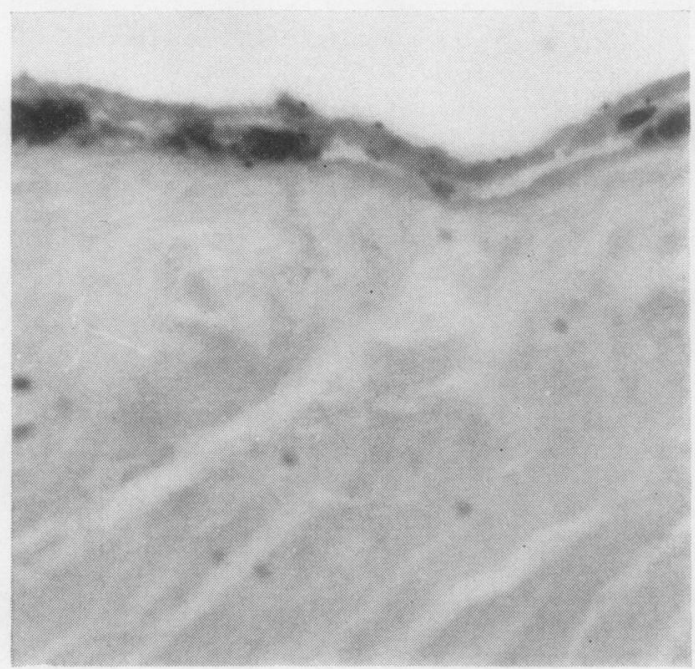

(b)

FIG. 10. (a) Surface deposits of fibrin and mononuclear cells and neutrophils on a typical acellular cusp two years after grafting. $H$. and $E$. $\times 105$. (b) Higher magnification of $(a)$. There is a superficial resemblance to endothelium. $H$. and $E$. $\times 380$.

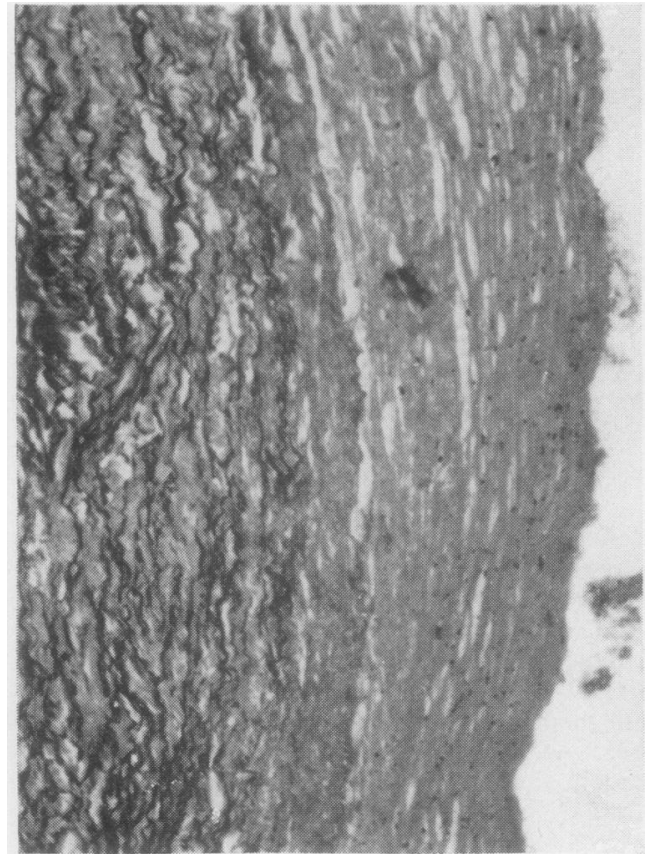

FIG. 11. Developing upper fibrous sheath at 6 wreks. Elastic tissue of the lpper portion of the graft sleeve lies to the left. Covering this is a deposit of fibrin containing strands of fib:ous tissue in its deeper layers and degenerate neutrophils and mononuclear cells near the luminal surface. E.V.G. × 105 . mononuclear cells and neutrophils were also present in the fibrin films. In the two-and-a-half-month graft the whole of the intimal surface of the graft sleeve was covered by fibrin containing haphazardly arranged mononuclear cells, fibroblasts, and neutrophils. Fine fibrils of fibrous tissue were present in the deeper layers, and the long axes of the cells lay parallel with the surface. This sheath tapered off at the line of attachment of the cusps, extending on to them for 1-2 mm. as a thin deposit of fibrin only. The lower had a composition similar to the upper one but extended only halfway up the lower sleeve. The organizing granulation tissue at each suture line contained a moderate number of chronic inflammatory cells. A thin, almost continuous layer of fibrin covered the aortic surfaces of the cusps, but only a few discrete deposits were seen on the ventricular surfaces. Within this fibrin a few scattered large mononuclear cells were present and had a palisade arrangement. Strands of fibrin and occasional cells extended into the superficial layers of the cusps. No endothelium was present on the graft, but where the developing intimal fibrous sheaths tapered on to host aorta above and ventricular endocardium below a single layer of irregular, slightly flattened cells, continuous with and resembling host endothelium, covered the luminal surface of the sheaths for a short distance. The host reaction at the graft/host interface, where the outer surface of the graft sleeve is in contact with the intima of the host valve ring, in the first week was limited to a mild acute inflammatory exudate at each suture line. This was within the host tissue, and only a few macrophages and neutrophils were found in the graft in this vicinity. Exposed, necrotic graft muscle at the lower suture line was 
infiltrated by macrophages and neutrophils. In grafts of one and two and a half months a thin layer of granulation tissue was seen in the host aortic ring at the graft/host interface.

Grafts between three and five months old showed little increase in the extent of the intimal fibrous sheaths, which usually tapered off to a fibrin tip in the region of the cusp attachment. Usually one or other sheath extended on to the cusp surface for a short distance not exceeding one-quarter of the length of the cusp and usually for less than one-sixth of this length. In grafts of this age there was a marked increase in the fibrous tissue content and thickness of the intimal fibrous sheaths. The collagen fibres lay parallel with the surface and were more numerous in the deeper layers. Scattered fibroblasts were present, their long axes parallel with the surface, and were more numerous in the superficial layers. A layer of flattened cells continuous with host endothelium extended on to only the upper and lower extremities of the intimal sheaths. No inflammatory reaction was seen in the sheaths. The cusps of these grafts were partially covered by thin deposits of fibrin extending for a variable distance from the tips of the intimal fibrous sheaths. In one graft almost the whole of the cusps were covered, but in most the fibrin was present as discontinuous plaques. These deposits usually contained or were partially covered by a few large rather flattened mononuclear cells and occasional neutrophils. Strands of fibrin and cells extended beneath both surfaces of the cusps.
In this group is the only graft (four and a half months) in which a fibrous sheath not continuous with the sleeve intimal sheaths was found on a cusp surface. This patient had only a single cusp homotransplant as a replacement for a shrivelled synthetic leaflet inserted previously for cusp perforation. Both the other cusps of the aortic valve were the patient's own tissue (Fig. 12). A thin layer of organizing granulation tissue and fibrous tissue, similar to the sleeve fibrous sheaths, was present on part of the ventricular surface of the homograft cusp, extending from the region of the line of closure to the free margin. The intimal fibrous sheaths on this graft sleeve extended only to the line of cusp attachment, and between this point and the sheath on the marginal third of the cusp the graft surfaces were bare.

At three months the acute inflammatory reaction at the suture lines in the host was replaced by a foreign body reaction to suture material, and poorly cellular organizing granulation tissue extended from these points into the intervening host sleeve and in some cases extended into the outer layers of the graft sleeve. However, in four grafts at this age there was only a foreign body reaction in the host around the sutures and the intervening tissue contained no inflammatory infiltrate. Graft adventitia lay directly on host intima, the two sleeves being distinguished only by the acellular nature of the graft sleeve. In one graft at four months there was a heavy chronic inflammatory infiltrate at the graft/host interface, and in another there was an appreciable foreign body type

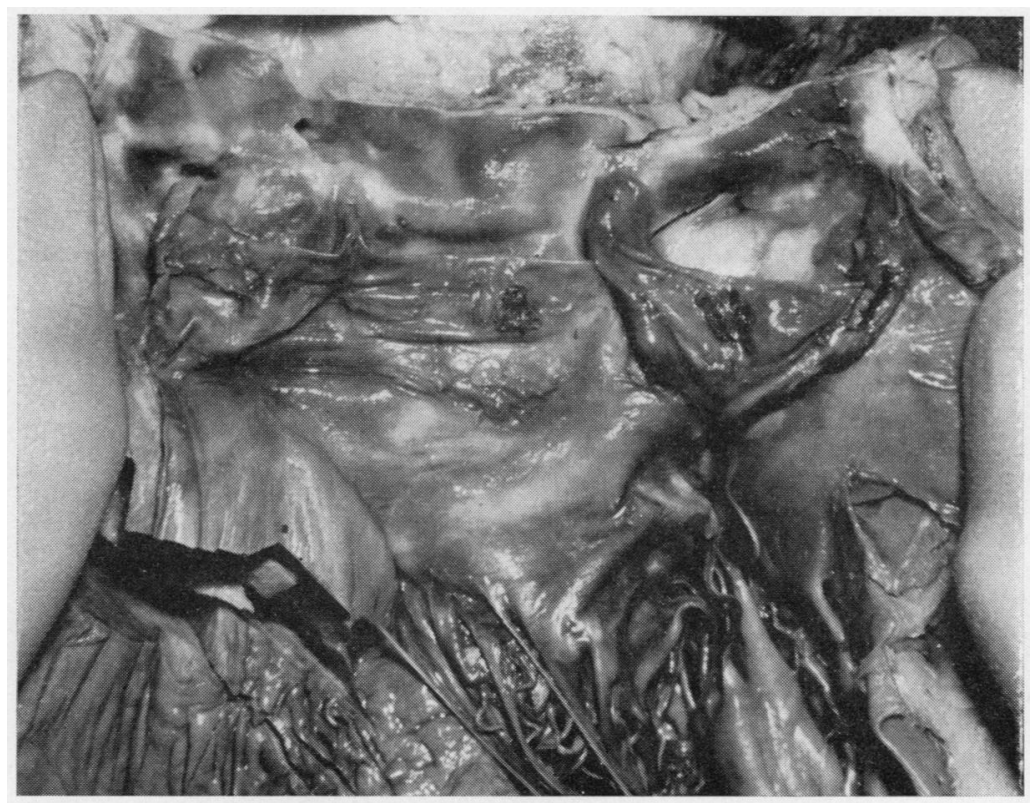

FIG. 12. Single cusp replacement at $4 \frac{1}{2}$ months. Only the left coronary cusp has been transplanted. There is thickening at the lower suture line partly caused by the lower intimal fibrous sheath. 


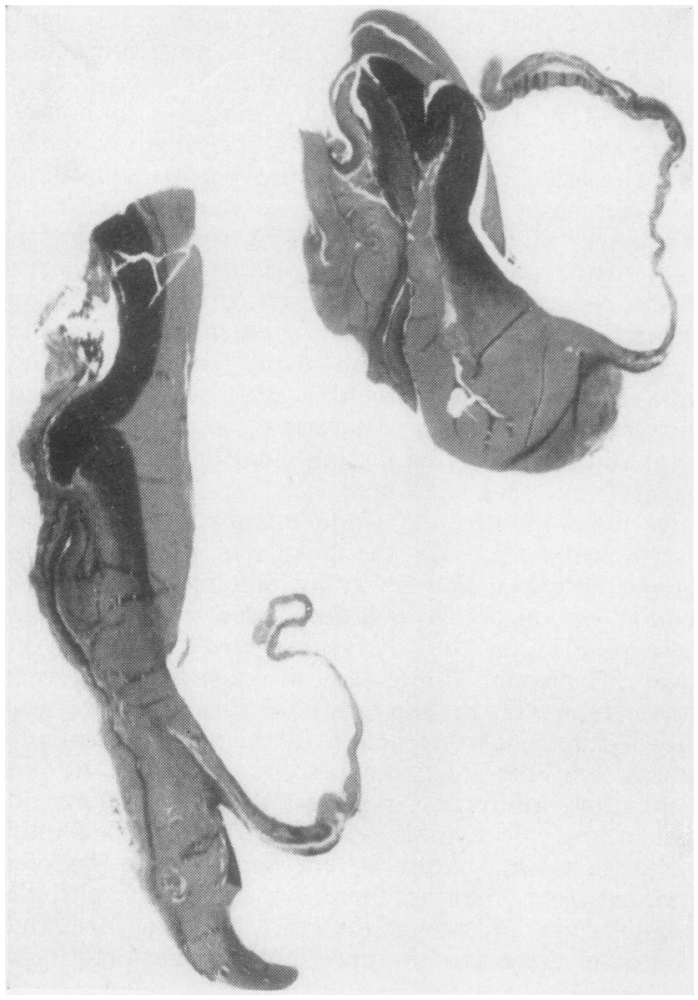

FIG. 13. Extent of intimal fib $\%$ ous sheaths at 24 months. The upper sheath ends above the cusp attchment. The lower extends for a short distance on to the inferior surface of the curps. E.V.G. $\times 2$.

infiltrate extending from the lower suture line into the lower portion of the graft sleeve. Host intimal fibrous sheath covered the more peripheral part of this exudate and organizing granulation tissue extended from it into the cellular area. (One graft at four and a half months had ruptured, and the appearance of this specimen will be described with the other torn specimens.)

Graft elastic and n̂brous tissue appeared a little condensed, this being more obvious in the aortic media of the upper sleeve, where smooth muscle was absent. This, and the acellularity, distinguished graft from host.

In grafts present for longer than five months there was little variation in host reaction. In all but three $(8,9$, and 15 months) the intimal fibrous sheaths extended no further than in grafts less than five months old. It was not unusual for one or other sheath to cover only part of the sleeve and not to reach the vicinity of the cusp attachment (Fig. 13). Fibrous tissue replaced the fibrin in the superficial layers, and fibroblasts became fewer and less obvious in the older specimens (Fig. 14). Only one (15 months) showed fibrin deposition on the surface of the mature fibrous sheath, and in this case a second sheath was forming over the surface of the original one at the $\tau$ upper and lower suture lines. There was no inflammatory infiltrate between the host sheath and graft sleeve except in a ruptured graft (seven months). Occasional capillary channels were seen in the deep layers of the sheaths.

Three grafts showed extension of one or both intimal fibrous sheaths on to the cusps. The specimen at eight months showed extension of the upper sheath along two-thirds of the aortic surface of the noncoronary cusp (Fig. 15). This valve had been sterilized with beta-propiolactone but not freeze-dried. The portion of the cusp covered by the sheath was acellular ? and the collagen appeared condensed but otherwise normal, as did the other cusp sectioned. However, the marginal third of the non-coronary cusp was bare and showed advanced degeneration (Fig. 16). Elastic tissue was absent and the fibrous tissue was brightly eosinophilic and granular, appearances similar to those seen in some of the ruptured valves. The ninemonth specimen showed extension of the lower sheath on to both sectioned cusps almost out to the free border. In this case the donor cusps were cellular (active fibroblasts) and host sheath and donor cusp fibrous tissue were indistinguishable (Fig. 17). Donor

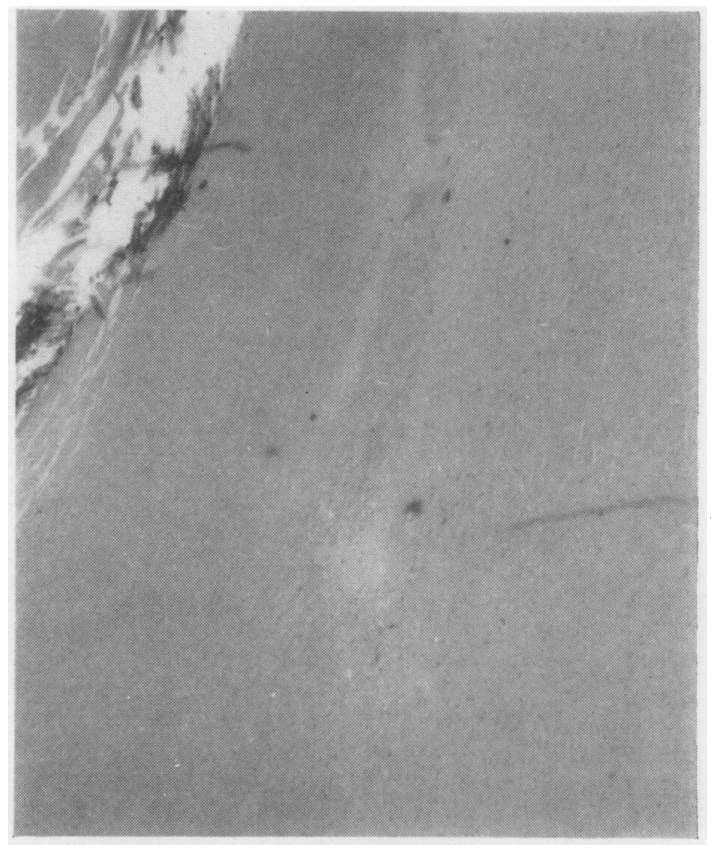

FIG. 14. The vpper intimal fibrous sheath at 29 months. This is at the upper suture line. Fragments of suture material are seen in the upper left corntr. To the right of and below this is acellular graft upper sleeve. Covering this (extreme right) is the intimal fibrous sheath. This contains scattered fib oblasts. There is no inflammatory reaction between sheath and graft. $H$. and $E$. 45 . 


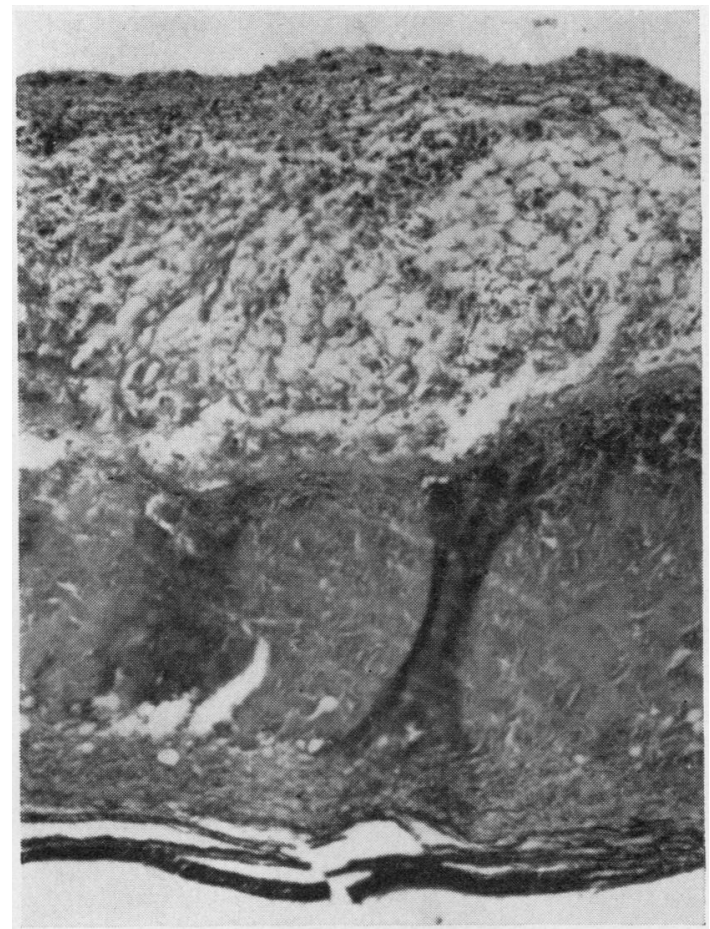

FIG. 15. Host fibrous sheath on the aortic surface of the non-coronary cusp at 8 months. The loose cellular sheath contrasts with the compact acellular doror cusp be'ow. E.V.G. $\times 115$. cusp elastic tissue splayed out into host fibrous sheath. This graft had been taken sterile and stored three days in nutrient medium before insertion. The third case also had been taken sterile and had not been freeze-dried. It had been stored in nutrient medium for 24 days before insertion. (Details of treatment of individual valves of three months and over are listed in Table I.) Both sectioned cusps were almost completely covered by continuations of the upper and lower intimal fibrous sheaths (Figs 18 and 19). In this case the donor cusps were markedly condensed and at the tips the collagen was disrupted. No cells were present in the graft cusps and the sheaths contained only fibroblasts (Fig. 20). Elastic tissue on the ventricular surface of the cusps splayed out into the lower host sheath. The only other case without bare cusps was the 27-month specimen, but in this case abacterial thrombi partially covered the aortic surfaces (Fig. 21). This valve had been taken sterile and stored 14 days in nutrient medium before use. The patient had been in severe congestive heart failure for some weeks and had multiple organizing infarcts in both lungs, pulmonary emboli, and mural thrombi on a posterior scar in the left ventricle.

Host reaction at the graft/host interface was usually that of mild chronic inflammation. Small numbers of vascular channels with scattered lymphocytes, macrophages, and plasma cells were present and extended into the outer layers of the graft sleeve (Fig. 22). From this zone fibroblasts extended sparsely but widely into the fibrous tissue of the graft sleeve but not into the elastic tissue in the upper part of the graft sleeve. There was no accompanying inflammatory cell infiltrate, although a few small

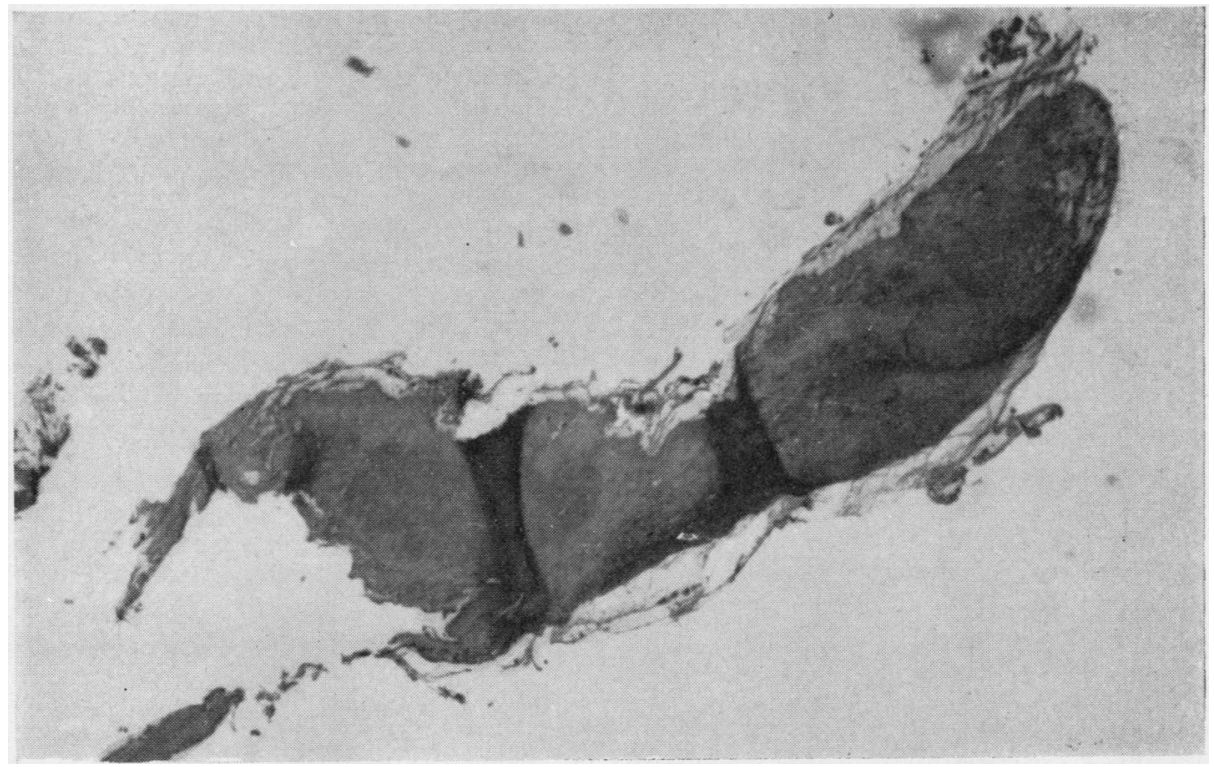

FIG. 16. Degenerate tip of the non-coronary cusp beyond the host sheath on the graft at 8 months. E.V.G. $\times 45$. 


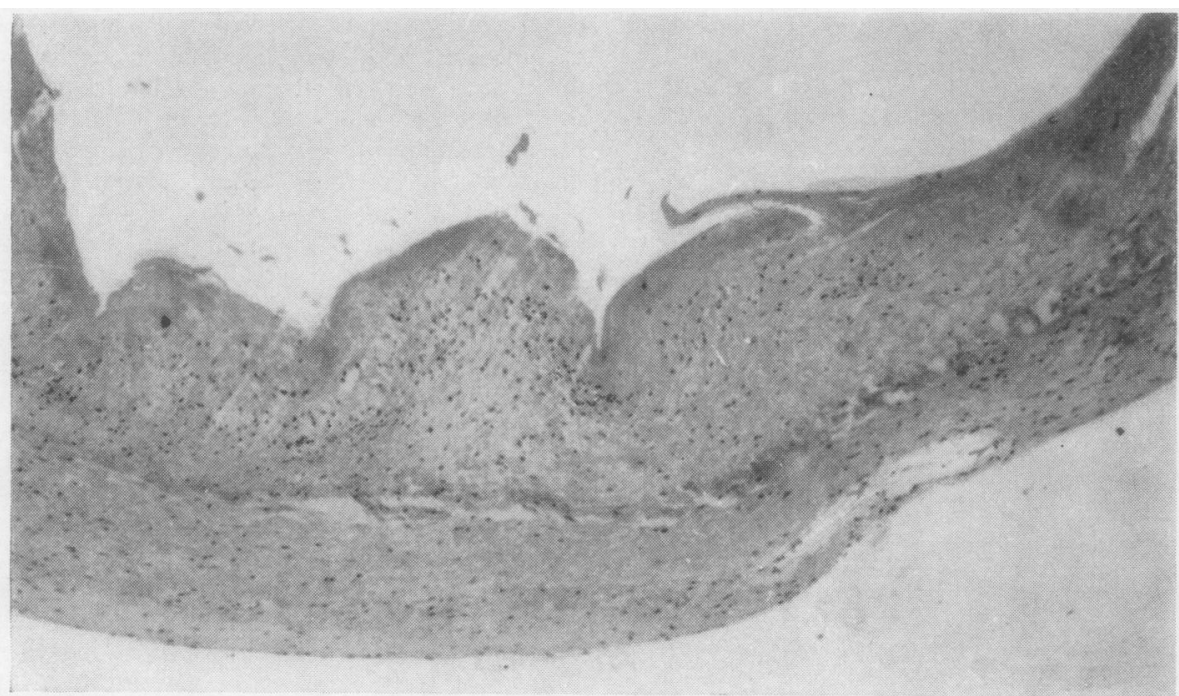

FIG. 17. (a) Graft at 9 months. This valve had an almost complete host sheath covering the ventricularis of the sectioned cusps. This is the only graft in which the donor cusps were cellular. Donor cusp above; host fibrous sheath below. H. and E. $\times 45$. (b) Higher magnification of $(a)$. The cells in the donor cusp are predominantly fibroblasts. Donor cusp above; host sheath below. H. and E. $\times 115$.

endothelial-lined channels extended from the host into most of these graft sleeves. In three grafts over five months $(7,15$, and 24 months (J. N.)) there was a heavy and extensive chronic inflammatory infiltrate, and in the seven-month case this extended through the graft ring to the ruptured cusp (Fig. 23). In these three cases lymphocytes, plasma cells, and macrophages were present in equal numbers. Eosinophils were usually present, and in two of these cases (7 and 24 months) and in the rupture at four and a half months they were present in relatively large numbers.

Grafts present over five months remained acellular except in the sleeve, where host fibroblasts were found in the region of the graft/host interface and were more numerous and more widely present in the older specimens. At nine months most of the lower sleeve was diffusely populated by fibroblasts, and in grafts at 17 months and older most of the graft sleeve, with the exception of the elastic tissue at the upper suture line and a thin rim of tissue lining the sinuses of Valsalva, was sparsely infiltrated by fibroblasts. In these specimens, without knowing the field examined, it was difficult to distinguish host and graft aortic rings. In contrast, the cusps remained acellular and fibrous tissue was condensed. In thin sections of intact grafts it could be seen that the coarsely laminated structure of the cusp fibrosa had been largely replaced by a finely fibrillary pattern. In valves at 27 and 29 months the cusps had a finely granular appearance. Staining reactions were normal, but thin strands of van Gieson (b) negative material were often found in the superficial layers of the fibrosa and were often, but not always, 


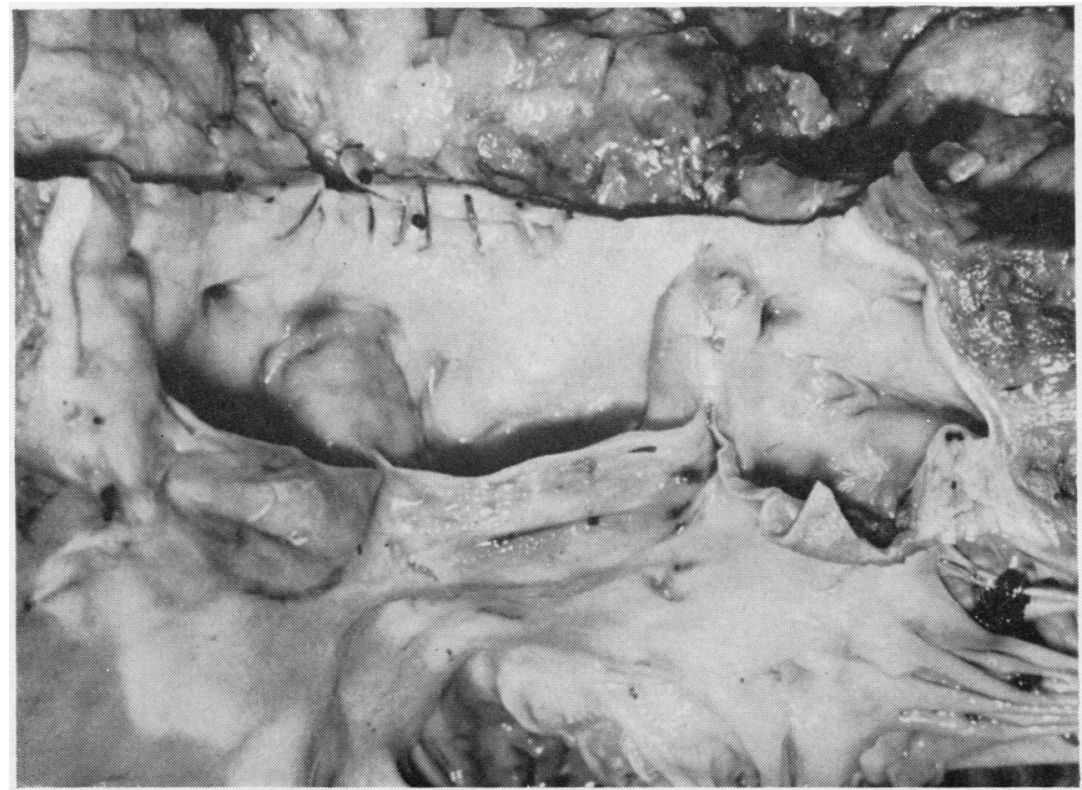

FIG. 18. Graft at 15 months. The aorta has been cut longitudinally and opened out at the right/left coronary cusp commissure. There is slight thickening of the cusps but they remain quite pliable. This is probably best seen in the cut edge of the left coronary cusp (right of picture). There was no clinical or pathological evidence of obstruction or incompetence. This is the only graft with an almost complete sheath extending over both surfaces of the cusps. The suture lines are hidden by the sheaths.

associated with surface deposits of fibrin. Elastic tissue appeared only condensed, but in transplants of two years and longer the high-power objective showed early fragmentation in the upper sleeve (Fig. 25 ). The subendothelial elastic layer of the aortic vestibule was focally disrupted where it was covered by the lower intimal fibrous sheath in most grafts. Usually only a single such focus occurred in any one section. This change was also seen in grafts of three months of age. It was found only in areas covered by host fibrous sheath. In the intact cusps elastic tissue was present as a single, thick, wavy layer, but in one case at 24 months (C. C.) and in the 27-month graft, cusp elastic tissue was reduced and in the former was present as an intact but very tenuous layer.

Nine grafts of over five months' duration had been both sterilized and freeze-dried. Of the other seven, two had been sterilized only ( 8 months ; 24 months (C. C.)), two had been taken sterile and freeze-dried (24 months (I. McI.) and 29 months) and three $(9,15$, and 27 months) had been taken sterile and stored in nutrient medium (Table I).

Remnants of necrotic cardiac muscle were found in grafts of up to two years' standing.

Calcification was often seen, but in many cases was associated with atheromatous changes which frequently had been noted before insertion. Residual host calcification was very often seen and deposits often protruded into the outer aspect of the graft sleeve. Five grafts showed calcification either of the transplant or associated with it. All were older grafts (15, 17 (P. M.), 24 (I. McI.), 24 (J. N.), and 29 months). In one (15 months) grafted tissue was not involved. The deposit was a small one involving fibrinous material at the surface of the lower host intimal fibrous sheath. This graft was also invaginated from without by extensive residual calcific deposits in the host valve ring (Fig. 19). The other four cases showed graft involvement. In the 24-month specimen the sleeve elastic tissue was compressed and distorted at the upper suture line and showed focal calcification. In two cases (17 and 29 months) the deposits were in the annulus and were extensive. In the 17-month transplant the deposit lay in the annulus of the ruptured cusp but did not extend into the cusp tissue which bordered the rupture. A single focus lay in each of two of the walls of the sinuses of Valsalva above the intact cusps in J. N. at 24 months (Fig. 26). The 29-month graft had a complete ring of calcification in the annulus. Invariably the deposits lay in acellular graft tissue in the sleeve. In no case did the calcified areas or immediately surrounding tissue contain any host fibroblasts, although these were usually present in other parts of the graft sleeve. 


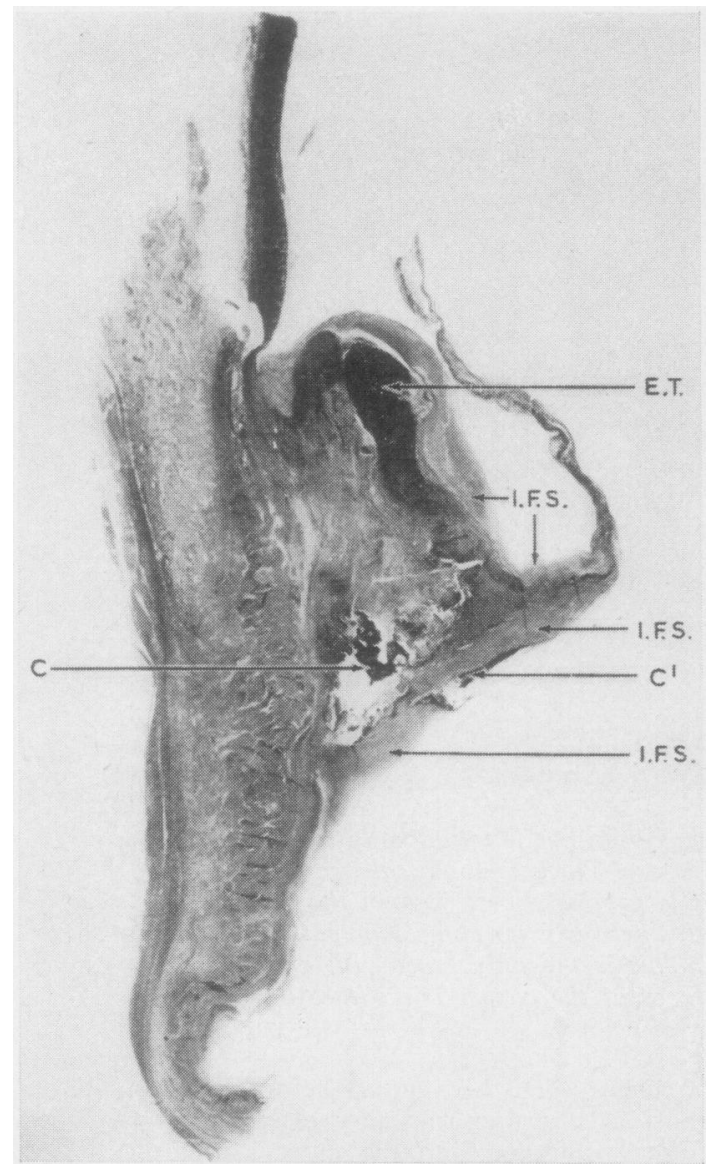

FIG. 19. (Left) Longitudinal section of the non-coronary cusp of the graft at 15 months. Host ring has buckled at the upper suture line and the graft protrudes into the limen. Elastic tissue is well preserved (E.T.). Host calcification $\overline{\bar{c}}$ (c) invaginates the graft lower sleeve. A linear deposi of calcification is seen in host lower intimal fibrous sheath (C1). The intimal fibrous sheaths (I.F.S.) completely covered this cusp and are best seen near the cusp attach-o ment line. Absence of the cusp-free border is a processing artefact. E.V.G. $\times 1.5$.

Although the cusps (with the exception of the graft at nine months) were acellular no calcification was seen in them. The four transplants showing calcifica- iv tion had been freeze-dried. Two had been sterilized with beta-propiolactone and two had been $\operatorname{taken}_{\vec{A}}$ sterile.

GRAFT RUPTURES Eight of the 53 grafts had rup- $\overrightarrow{-}$ tured. Another valve removed at eight months for peripheral detachment at the suture line was intact $\overline{\widehat{\sigma}}$ but showed degenerative changes in the non-coronary cusp, similar to those seen in six of the ruptured $\overrightarrow{0}$ valves. These transplants ranged from four and a half $\underset{ }{ }$ months to 25 months after grafting. The donor valves: were from patients aged from 17 to 63 years ando had been removed from six to 48 hours after death. They had been stored from 11 days to three months before insertion. Comparable time lapses were found in non-ruptured valves. All ruptured valves had been $\underset{\Omega}{\mathbb{D}}$

FIG. 20. (Below) Graft at 15 months. Fib rous sheaths com pletely envelope the cusp-free border. Fragmenting donor? cusp collagen (D.C.) is seen between the confluent sheaths The cells are fibrob!asts. This is the only graft with this appearance. $H$. and $E$. $\times 125$.

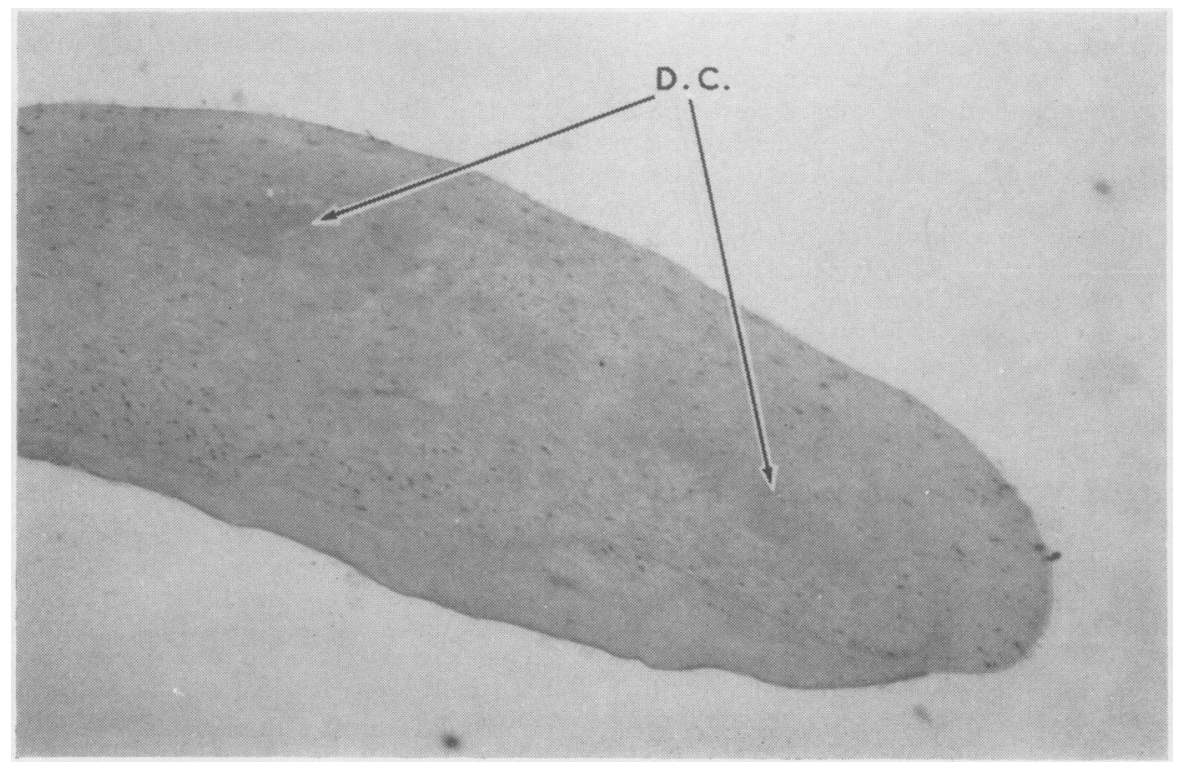




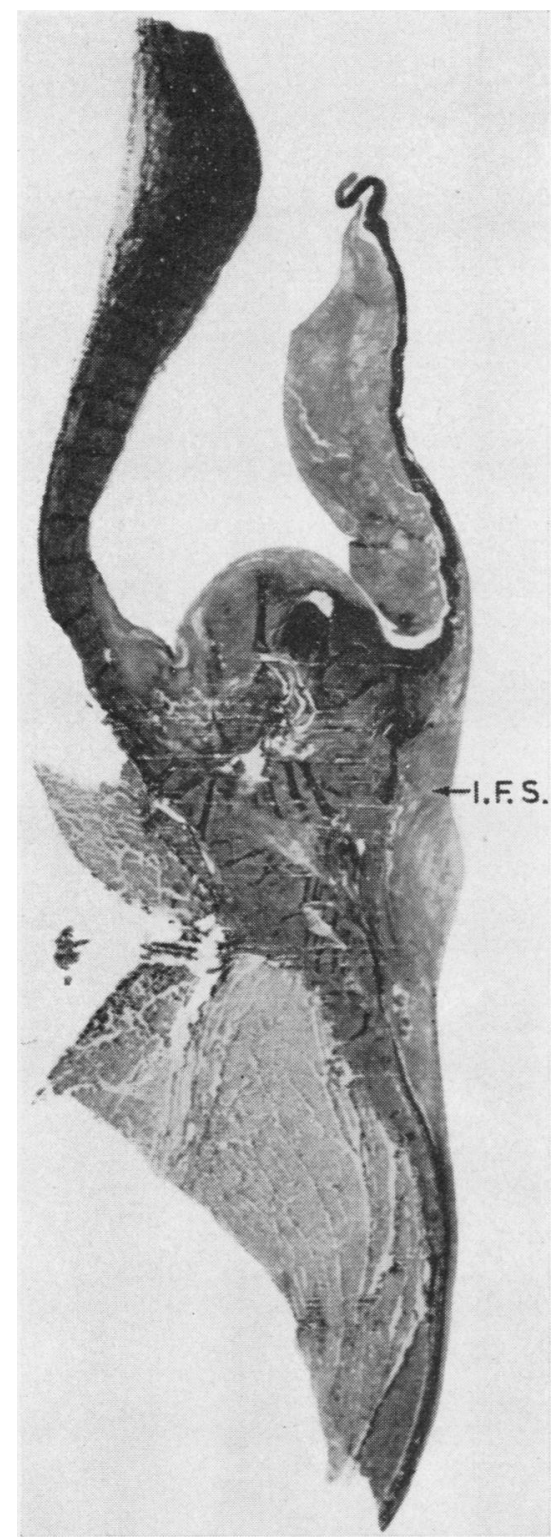

FIG. 21. Thrombus on the aortic surface of the right coronary cusp at 27 months (see Fig. 7). The lower intimal fibrous sheath (I.F.S.) extends on to the ventricularis for one-quarter of the cusp length. The sheaths are no thicker than those seen in the 15-month graft (Fig. 19). E.V.G. $\times 2$.

freeze-dried. This had been carried out twice in the six-month rupture. All but one had been sterilized with beta-propiolactone and one 17-month case (P. M.) had been sterilized twice. The intact graft showing degeneration of one cusp (18 months) had been sterilized but not freeze-dried (Table II). The ruptures were not confined to a particular cusp, and in three patients two tears were present $\left(4 \frac{1}{2}, 17\right.$ (A. M.), and 17 (P. M.) months). All the torn cusps were bare and in the intact degenerate cusp (eight months) the area of degeneration was sharply defined and limited to the marginal third of the non-coronary cusp immediately beyond the host fibrous sheath, which covered two-thirds of the aortic surface of this leaflet. None of the ruptures was associated with thrombi or vegetations. Calcification was found in two of the ruptured grafts but was not directly related to the tears. In the 17 -month case (P. M.) with perforation of the right cusp belly, calcification was present in the corresponding part of the annulus but not in the intact portion of leaflet intervening between the annulus and the rupture. In the 24-month cas? (I. McI.) with a right cusp commissure tear, the elastic tissue of the upper part of the graft sleeve was calcified.

Histological appearances divided these grafts into two groups. In two (four and a half months and 24 months (I. McI.)), degeneration was focal and was limited to the area of rupture. Both valves had been freeze-dried, but only the earlier one had been sterilized. Elastic tissue appeared normal but disappeared abruptly at the tears. No degenerative change was seen in immediately adjacent elastic tissue. In the 24-month graft the fibrin tip of the upper intimal sheath lay on the surface at the point of rupture, and fibrin-like material was present in the fibrosa underlying this. There was little change in the adjacent fibrous tissue. The area was acellular. The four-and-a-half-month case showed a very small fullthickness area of brightly eosinophilic 'fibrinoid' change in the fibrosa immediately surrounding the tear. This focus stained a khaki colour with the van Gieson stain. The fibrin tip of the upper intimal sheath coincided with the area of rupture and both this and the focus of degeneration were infiltrated by macrophages, lymphocytes, plasma cells, and relatively numerous eosinophils. One rupture in the second group was also associated with an inflammatory cell infiltrate. All other ruptures were acellular. No organisms were seen.

The other six ruptures and the intact valve with degeneration of one cusp showed extensive and pronounced fibrous tissue changes. In all but the intact graft the change involved the whole of the ruptured cusp and one or more of the intact leaflets. In the two 17-month grafts and the 24-month (J.N.) and 25-month valves all three leaflets were affected. All torn valves in this group and the intact partly degenerate one had been sterilized in betapropiolactone and all but the intact transplant had been freeze-dried (Table II). With haematoxylin and eosin, staining of the valve fibrosa was variable, much of it appearing pale and granular or having a watery appearance resembling oedema fluid. Other areas were brightly eosinophilic and amorphous with a 'fibrinoid' appearance (Figs 27 and 28). With van Gieson staining most of the fibrosa stained a yellowish colour and was amorphous. Some areas 


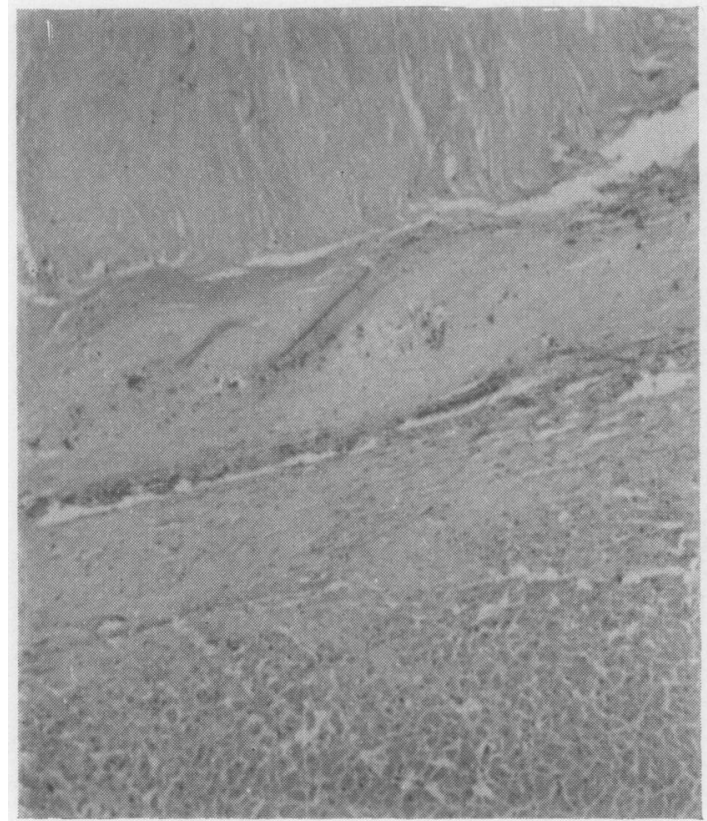

(a)

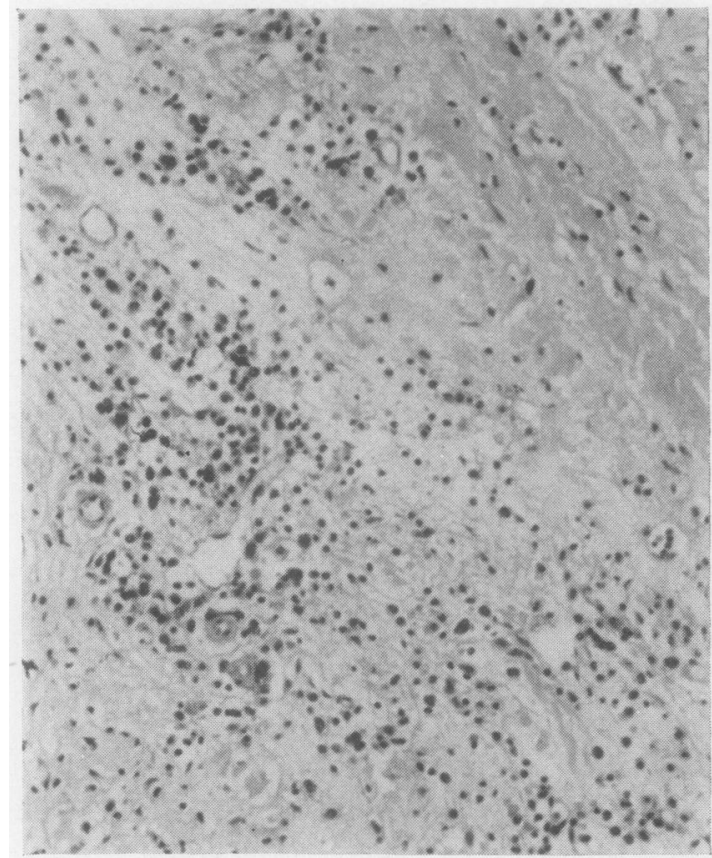

(c)

FIG. 22. Examples of cellular reaction at the graft/host interface in late grafts. (a) 24 months. This specimen shows little reaction. Host cardiac muscle below, graft lower sleeve above. Fibroblasts are present in the graft sleeve. $H$. and $E$. $\times 105$. (b) 27 months. Mild chronic inflammatory response. Host annulus occupies the left of the photograph. Graft on the right is infiltrated by fibroblasts and occasional lymphocytes and plasma $\bigcirc$ cells. H. and E. $\times 105$. (c) 25 months. A moderate chronic inflammatory infiltrate in organizing granulation $\mathbb{\mathbb { B }}$ tissue. Host is at the lower left, graft at the upper right. $H$. and $E$. $\times 105$. (d) 25 months. High magnification $\sigma$ of a small area in the lower left of (c) to show small blood vessels, lymphocytes, plasma cells, and macrophages. $H$. and $E . \times 380$. (b)

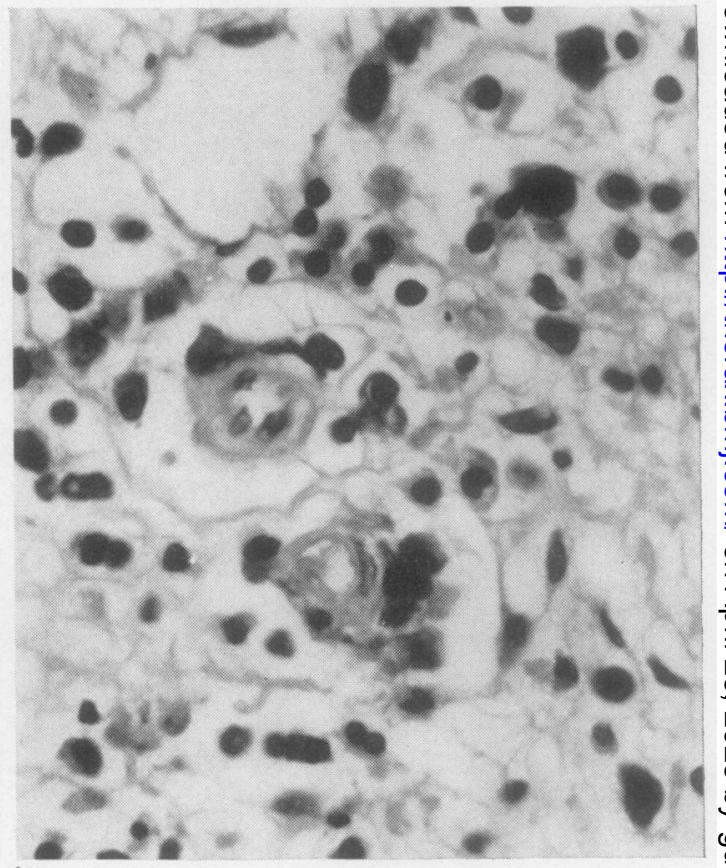

(d) 


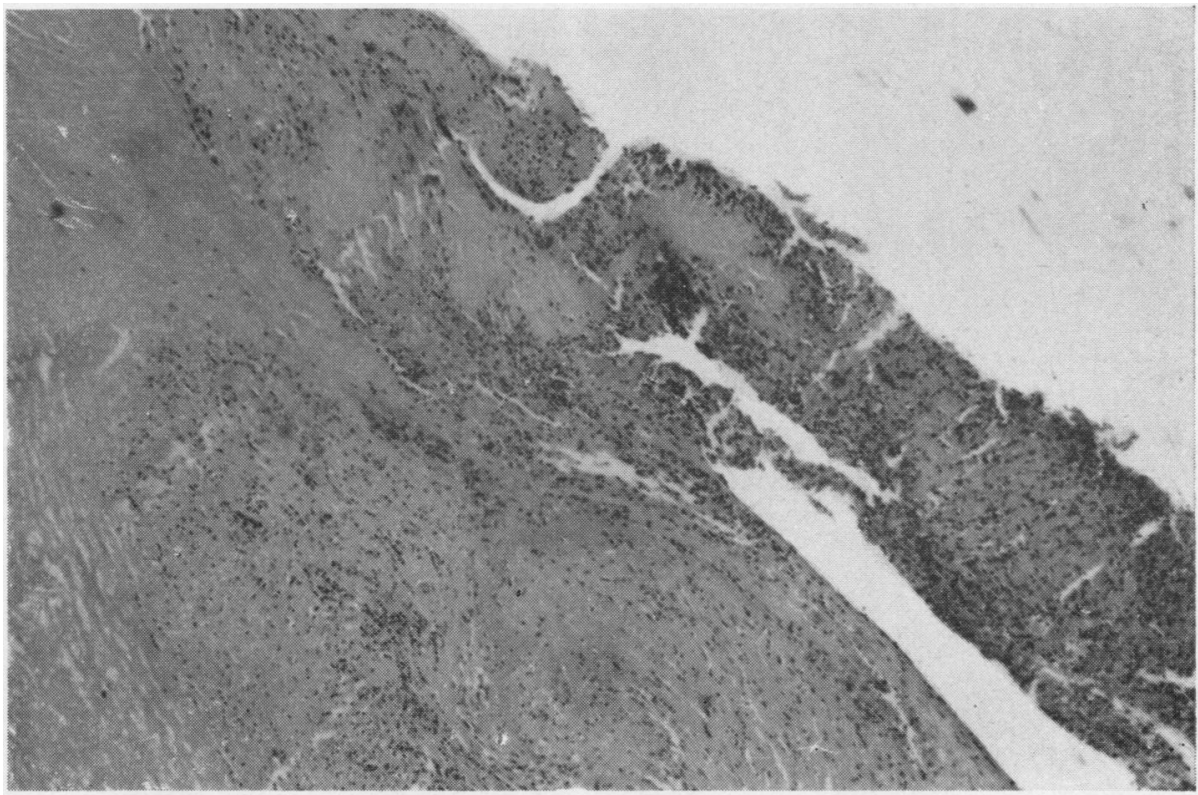

FIG. 23. Rupture at 7 months. There is an inflammatory infiltrate in the lower sleeve of the graft, adjacent intimal sheath, and degenerate cusp collagen (see Figs 4 and 29). $H$. and $E$. $\times 45$.

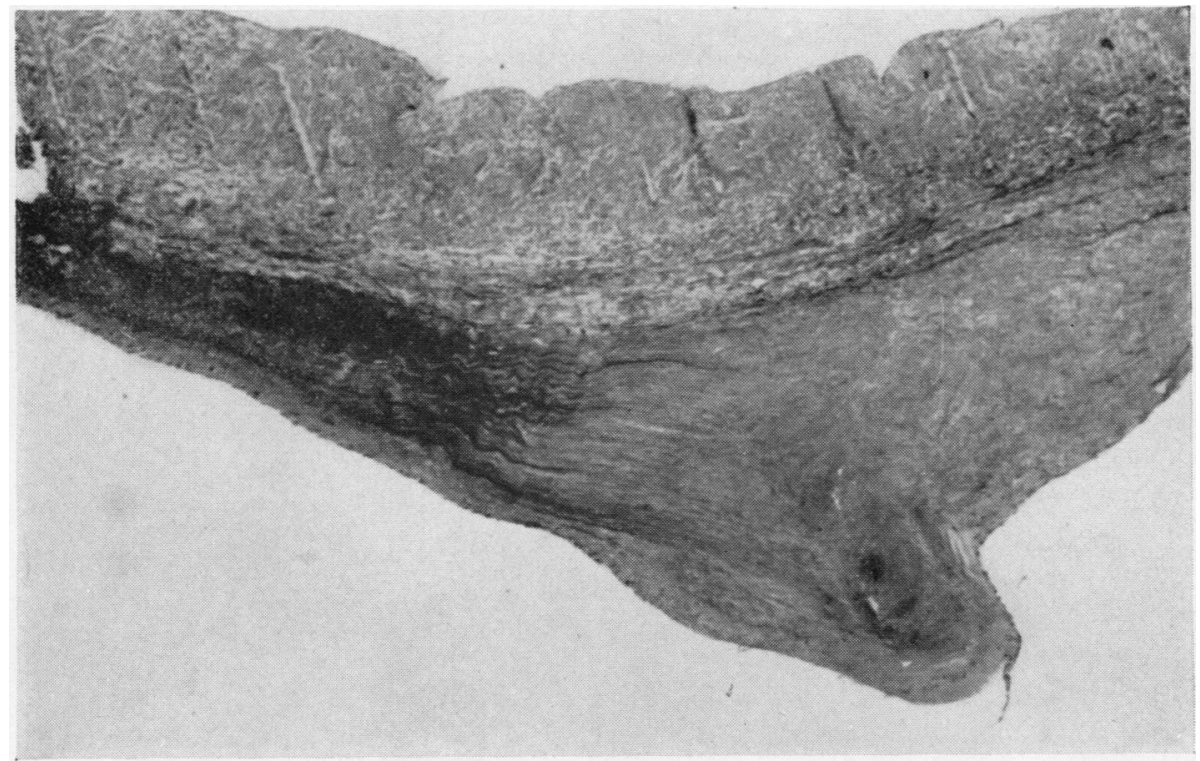

FIG. 24. A control cusp (non-coronary; patient aged 55 years). There is a fibro-elastic 'spur' on the ventricularis at the line of closure. These lesions are usually largest at the mid-point on the line of closure of the non-coronary cusp in older persons. They were seen in this form or as flattened plaques in older donor valves. E.V.G. $\times 125$. 


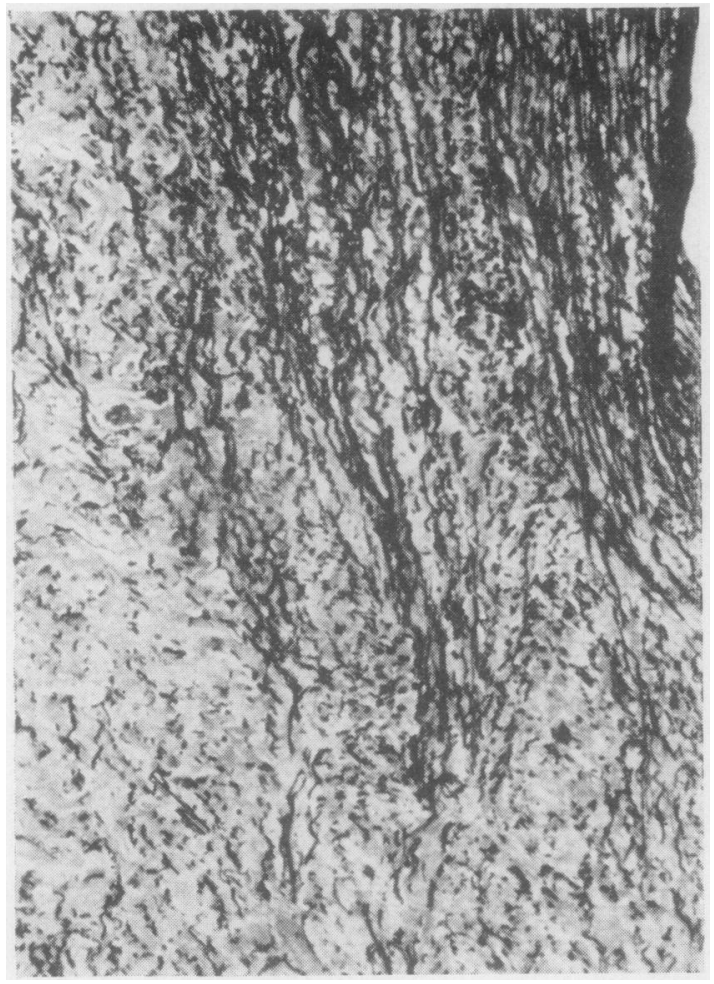

FIG. 25. Origin of aortic media elastic tissue in the upper part of the graft sleeve at 25 months. There is early fragmentation of the fibres. E.V.G. $\times 105$.

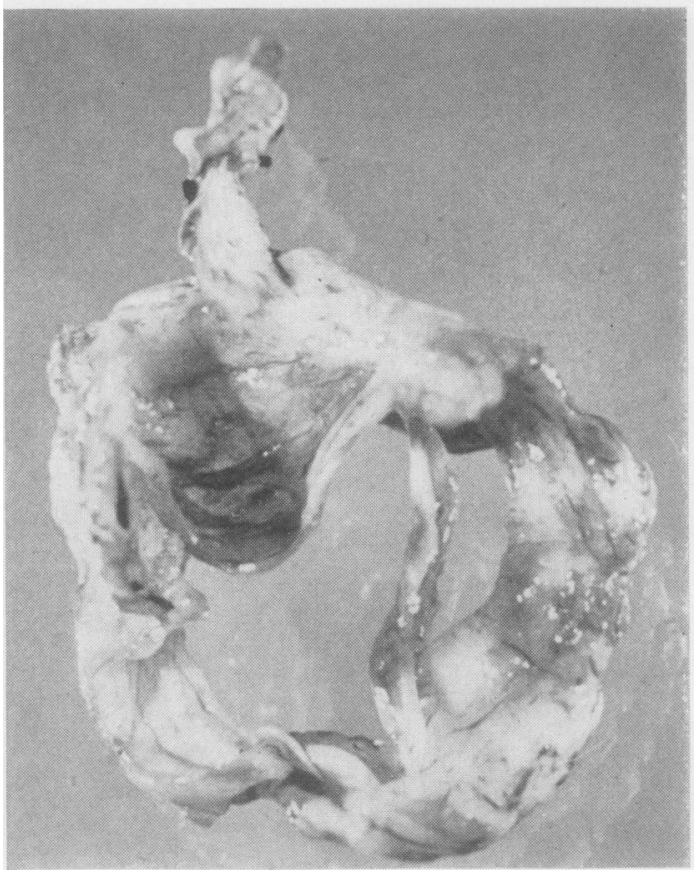

FIG. 27. Graft rupture at 17 months. This surgically excised specimen was removed because of recurrent aortic incompetence. There is a rupture of the belly of the left coronary cusp. All leaflets showed marked degenerative changes histologically (see Fig. 28).

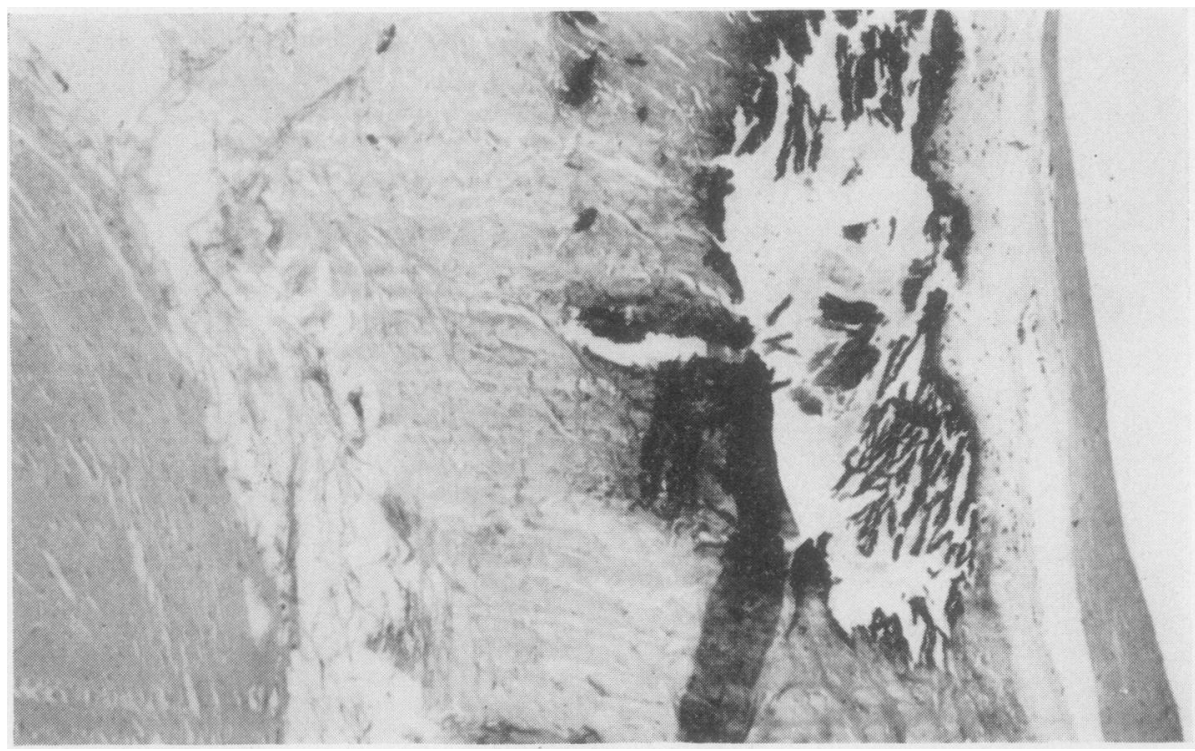

FIG. 26. Calcification in the wall of the sinus of Valsalva at 24 months. Host aortic sleeve at left, graft $\underbrace{0}$ aortic sleeve with calcification in the centre, and thin tapering tip of upper intimal fibrous sheath on the right. Note the lack of cellular response at the graft/host interface. $H$. and $E . \times 125$. 


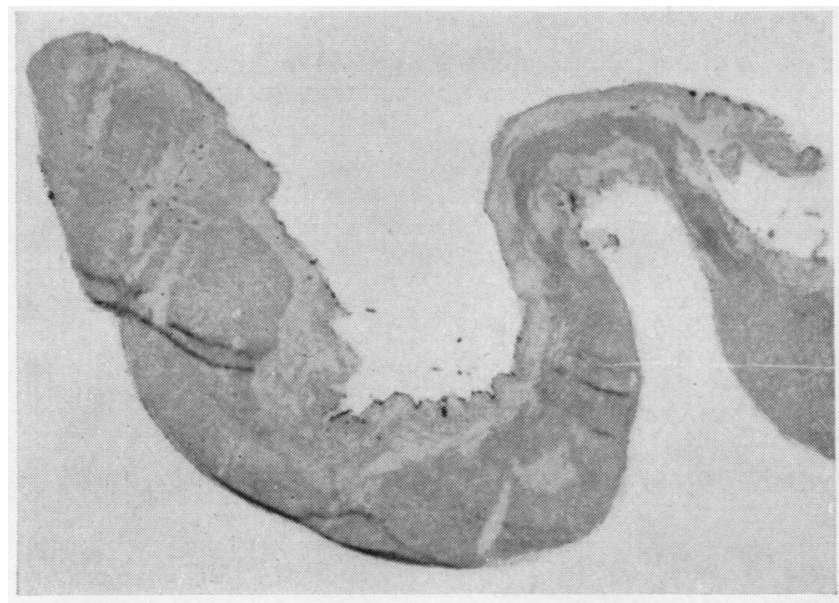

(a)

FIG. 28. Cusp degeneration in late rup tures. (a) Degeneration in the non-coronary (intact) cusp of 17-month graft with rupture of the bally of the right coronary cusp. Normal architecture is replaced by 'fibrinoid' material in the narrower region. Elsewhere the fibrosa had a pale watery appearance. $H$. and $E$. $\times 45$. (b) Higher magnifcation of a similar section to that seen in (a) stained with E.V.G. The dark areas stained a khaki colour. The paler tissue resembled oedema fluid. $\times 95$. (c) Degenerate cusp at 25 months. All semblance of normal architecture is lost. E.V.G. $\times 125$.

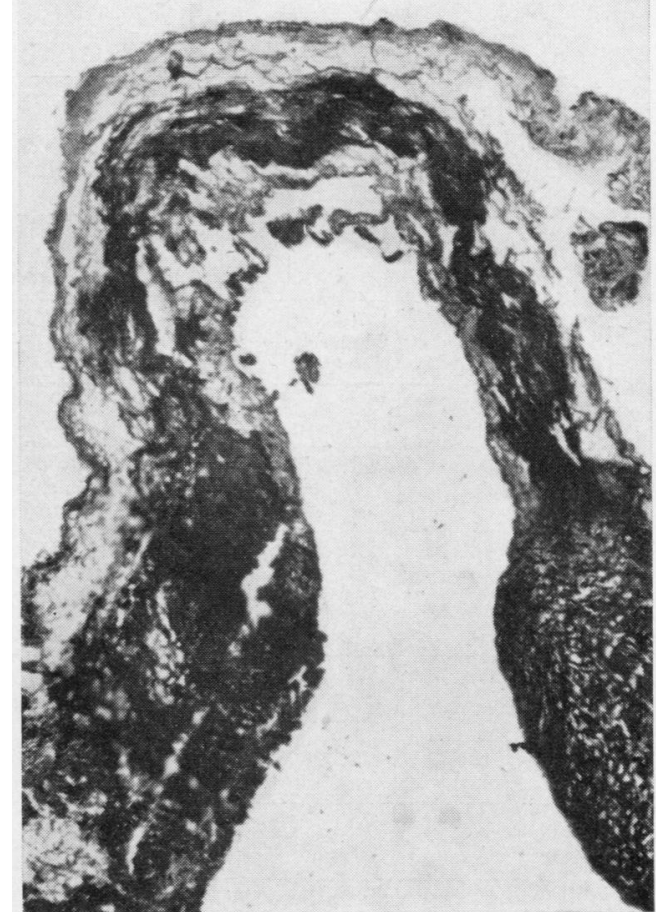

(b)

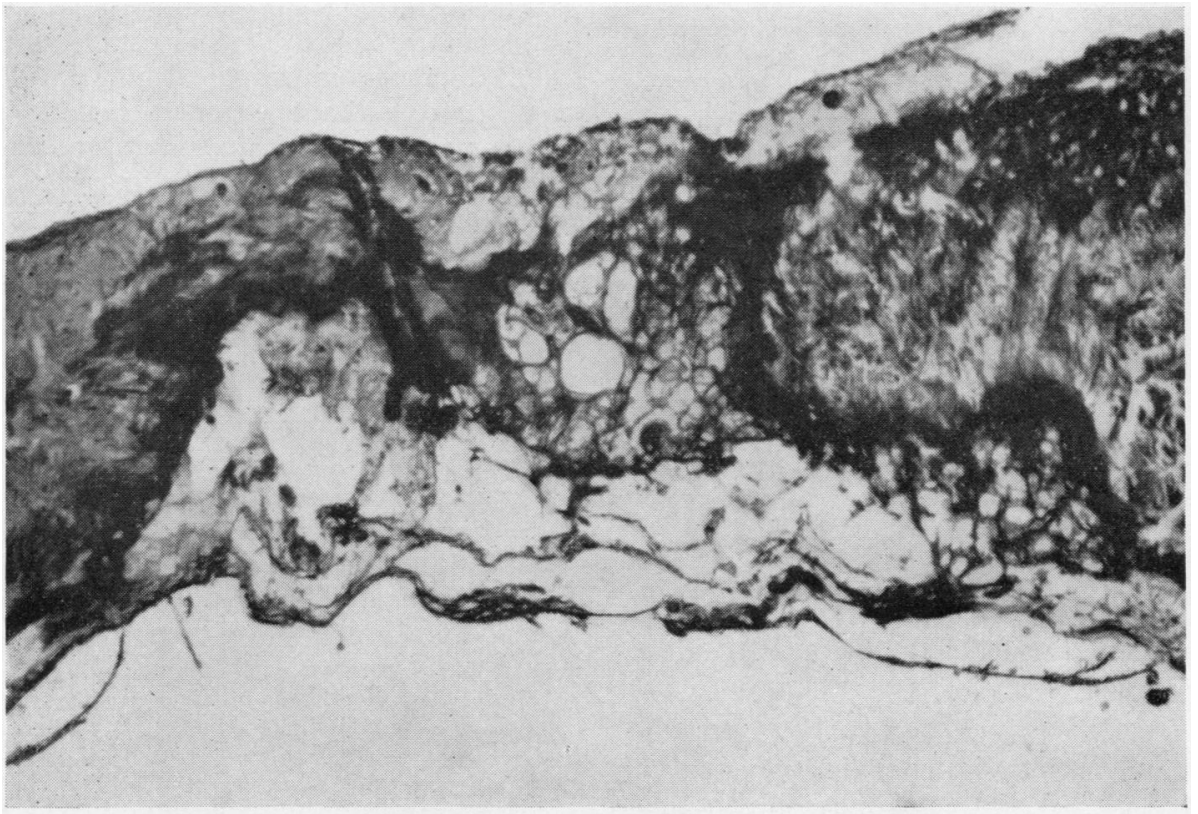

(c) 
T A B LE I I

DETAILS OF RUPTURED AND DEGENERATE DONOR VALVES

\begin{tabular}{|c|c|c|c|c|c|c|c|c|c|c|c|c|}
\hline Recipient & $\begin{array}{l}\mathrm{A} \\
\text { an } \\
\mathrm{Se}\end{array}$ & & Diagnosis & $\begin{array}{c}\text { Graft } \\
\text { Duration } \\
\text { (months) }\end{array}$ & $\begin{array}{l}\text { Site of } \\
\text { Rupture }\end{array}$ & Do & & $\begin{array}{c}\text { Donor } \\
\text { Cause of } \\
\text { Death }\end{array}$ & Treatment & of Valve & $\begin{array}{l}\text { Time } \\
\text { Stored }\end{array}$ & $\begin{array}{l}\text { Hours } \\
\text { post } \\
\text { mortem } \\
\text { before } \\
\text { Removal }\end{array}$ \\
\hline F..T. & 66 & $\mathbf{M}$ & A.S. & $4 \frac{1}{2}$ & $\begin{array}{l}\text { R.C.C. and } \\
\text { N.C.C. } \\
\text { (commissures) }\end{array}$ & 63 & & $\begin{array}{l}\text { Multiple } \\
\text { injuries }\end{array}$ & B.Pl. & F.D. & 2 months & N.S. \\
\hline R.N. & 43 & $\mathbf{M}$ & $\begin{array}{l}\text { A.I. } \\
\text { Hyperten- } \\
\text { sion }\end{array}$ & 6 & R.C.C. (belly) & 52 & $\mathbf{M}$ & $\begin{array}{c}\text { Carcinoma } \\
\text { bronchus }\end{array}$ & B.PI. & F.D. $\times 2$ & 3 months & 6 \\
\hline R.McK. & 48 & $\mathbf{M}$ & A.I. & 7 & L.C.C. (belly) & 29 & $\mathbf{M}$ & $\begin{array}{l}\text { Multiple } \\
\text { injuries }\end{array}$ & B.Pl. & F.D. & 1 month & 24 \\
\hline A.M. & 49 & $\mathbf{M}$ & A.I. & 17 & $\begin{array}{l}\text { L.C.C. (belly) } \\
\text { N.C.C. } \\
\text { (commissures) }\end{array}$ & 31 & $\mathbf{M}$ & Leukaemia & B.PI. & F.D. & 11 days & 48 \\
\hline P.M. & 42 & $\mathbf{M}$ & A.I.; M.S. & 17 & $\begin{array}{l}\text { N.C.C. (both } \\
\text { commissures) }\end{array}$ & 45 & $\mathbf{F}$ & $\begin{array}{l}\text { Multiple } \\
\text { injuries }\end{array}$ & B.Pl. $\times 2$ & F.D. & 2 weeks & 28 \\
\hline I.McI. & 57 & $\mathbf{M}$ & A.I. & 24 & $\begin{array}{l}\text { R.C.C. } \\
\text { (commissure) }\end{array}$ & 22 & $\mathbf{M}$ & $\begin{array}{l}\text { Head } \\
\text { injuries }\end{array}$ & & F.D. & 1 month & 12 \\
\hline J.N. & 65 & $\mathbf{M}$ & $\begin{array}{l}\text { A.S. } \\
\text { Hyperten- } \\
\text { sion }\end{array}$ & 24 & $\begin{array}{l}\text { L.C.C. } \\
\text { (commissure) }\end{array}$ & 59 & $\mathbf{M}$ & Carcinoma & B.PI. & F.D. & 12 days & 6 \\
\hline N.B. & 43 & $F$ & A.I. & 25 & N.C.C. (belly) & 17 & $\mathbf{F}$ & $\begin{array}{l}\text { Multiple } \\
\text { injuries }\end{array}$ & B.Pl. & F.D. & 6 weeks & 12 \\
\hline P.H. & 27 & $\mathbf{M}$ & A.I. & 8 & $\begin{array}{l}\text { Intact but } \\
\text { degenerate }\end{array}$ & 55 & $\mathbf{M}$ & $\begin{array}{l}\text { Myocardial } \\
\text { infarct }\end{array}$ & B.Pl. & & 3 weeks & 9 \\
\hline
\end{tabular}

A.S. $=$ aortic stenosis; A.I. $=$ aortic incompetence; M.S. $=$ mitral stenosis; L.C.C. $=$ left coronary cusp; N.C.C. $=$ non-coronary $\stackrel{\Omega}{0}$ cusp; R.C.C. $=$ right coronary cusp; B.PI. = beta-propiolactone sterilized; F.D. $=$ freeze-dried; N.S. = not stated.

took a purplish-red colour and in these foci fine, short, disrupted fibrils were seen splayed out but not in bundles. Elastic tissue was absent from the cusps except in the region of attachment. No structure identifiable as degenerate elastic tissue was seen. The surfaces of these cusps were bare. One graft (seven months) in this group had an extensive cellular infiltrate at the site of rupture. This graft had a cusp perforation and both the cusps sectioned were heavily invaded by chronic inflammatory cells adjacent to the cusp attachment. Both showed collagen degeneration. There was an extensive graft/host chronic inflammatory cell infiltrate, and this extended the full thickness of the graft sleeve and was confluent with the cellular exudate in both cusps and in the fibrin tips of the intimal sheaths which lay directly on the cusps in this region (Figs 23 and 29). Large mononuclear cells predominated in the cusp and eosinophils were relatively numerous. No organisms were seen.

In these ruptured grafts the appearance of the cusps was in marked contrast with that of the sleeves. These were diffusely but sparsely peppered with fibroblasts and the fibrous tissue showed no evidence of degeneration. Elastic tissue of the sleeves showed early fragmentation visible only with the high-power objective.

\section{DISCUSSION}

Two recent clinical studies compare the effects on the patient of different methods of coronary artery perfusion under heart-lung bypass condi- tions. Nelson and Cooley (1964), studying cardiac $\overrightarrow{\vec{O}}$ responsiveness at the end of operation, and 3 Austen, Corning, Moran, Sanders, and Scannell (1966), recording the post-operative courses of patients after aortic valve surgery, found a signifi- $\vec{F}$ cant difference in response between those with and those without coronary artery perfusion. $\stackrel{x}{x}$ Neither group found any significant difference in $\frac{5}{3}$ behaviour between those having perfusion of a single artery and those having both perfused. In 0 the present study, 19 of 22 patients who died in the first two weeks had significant recent myo- 욱 cardial necrosis, and in the eight patients who $\rightarrow$ died of massive subendocardial necrosis the distribution of the lesion was unlike ischaemia N associated with coronary artery disease. Four of these patients had dissections of one coronary artery but retained the integrity of the other. All thus had perfusion of one or both coronary arteries but nevertheless suffered massive myo- 0 cardial damage. Significant necrosis (either wide- $\mathbb{D}$ spread focal or anterior or posterior wall infarc-? tion) was found in the other 11 cases, and the high incidence of the lesions supports the clinical $\frac{\overrightarrow{\mathbb{D}}}{\mathrm{D}}$ arguments for adequate coronary artery perfu- $\cong$ sion.

The occurrence of coronary artery dissection. in the absence of medial disease was thought to 


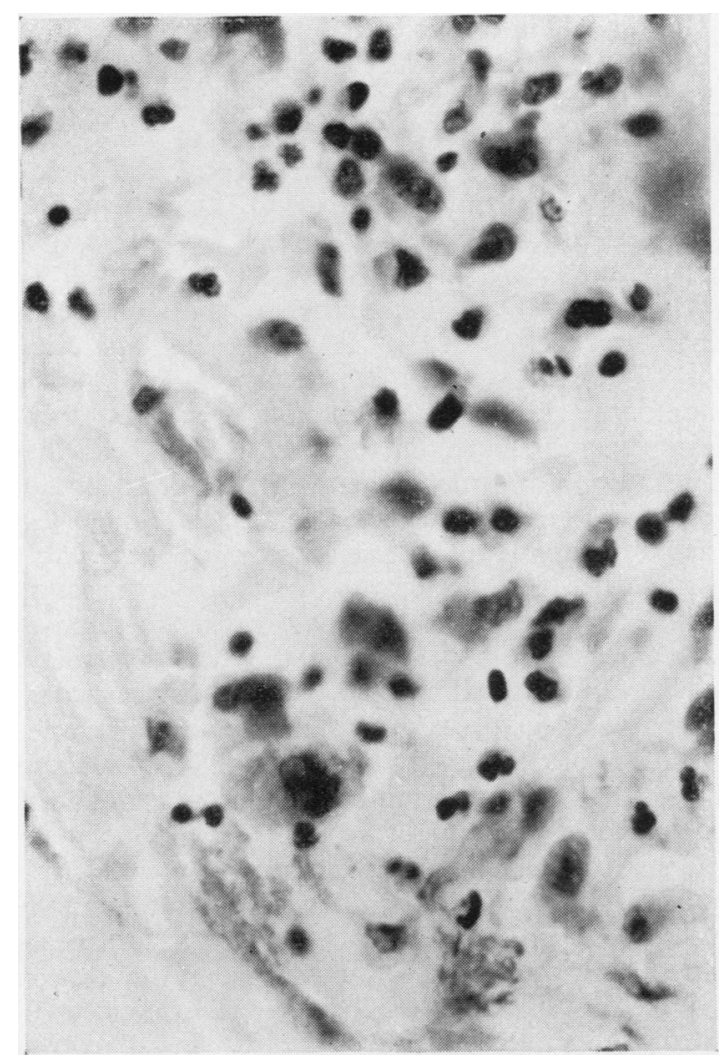

FIG. 29. Cellular infiltrate in cusp rupture at 7 months. Neutrophils, lymphocytes, plasma cells, and macrophages are present. The collagen of the fibrosa showed degenerative changes. $H$. and $E$. $\times 380$.

be related to the manner in which these vessels are related to the heart. Whereas the more commonly cannulated arteries and veins lie relatively loosely in a fibro-fatty layer in the leg, arm, or neck, the coronary arteries are more firmly attached to the epicardium, and any shearing force in cannulation is more likely to tear the vessels.

The high incidence of myocardial fibrosis as healed infarcts and focal lesions in the late deaths is probably in part a reflection of the acute damage seen in so many of the early postoperative deaths. However, six early and six late patients showed myocardial fibrosis in the absence of appreciable disease of the major coronary arteries, and this was distinct from the interstitial fibrosis of hypertrophied hearts. These scattered focal lesions were similar to those described by Schwartz and Mitchell (1962) as unrelated to main vessel narrowing but related to increasing age. Of the four most severely affected patients, three were under 35 years of age and one was 43 years old. The lesions were associated with fibrocellular and fibro-elastic intimal plaques in the smaller mural arteries and were distinct from the vessel thickening and perivascular fibrosis in the papillary muscles which were almost universally found in the enlarged hearts of this series. The vessel lesions resemble those seen in pulmonary arteries in lowflow and thrombo-embolic conditions as first described by Rich (1948) and since by Best and Heath (1958) and others, and it is suggested that alterations in flow caused by aortic valve disease may lead to low-flow conditions in the coronary arteries. Temple, Serafin, Calvert, and Drabble (1964) pointed out the role of the coronary arteries as a run-off in the prevention of turbulence in the ascending aorta under normal conditions. The converse of this may apply, and loss of laminar flow in the ascending aorta as a consequence of aortic valve disease may result in diminished coronary artery blood flow.

Experience and improved techniques have led to increasing survival rates in both man and the experimental animal in cardiac valve replacement. Sterilization and freeze-drying of donor valves provide a choice and availability of homologous material not otherwise possible in the human. In comparison with fresh material, these techniques introduced two aspects over and above the problems of surgical methods and the homograft reaction which have preoccupied most workers unti! recently. One is the direct effect of freeze-drying and the various methods of sterilization on the grafted tissues; the other, the host reaction to differently treated tissues. One per cent. betapropiolactone was used on those valves which were sterilized in this series. It has been stated that at this strength this agent causes little denaturation of tissue, kills organisms, and destroys itself by hydrolysis (Rains et al., 1956). Pritchard, Wright, and Johnston (1966) report that sterilization by beta-propiolactone produced a significant alteration in the tensile properties of human pericardium. Lower, Pillsbury, Angell, and Kosek (1966) thought high concentrations of antibiotics toxic to valve cusp tissues. They also found in orthotopic canine aortic valve homotransplants at six to 12 months a striking difference between valves which had been freezedried or stored in high concentrations of antibiotics and those which had been transplanted in the fresh state. The former were acellular and remained so. The latter retained their donor cells, but with increasing time were found to have a less orderly arrangement of collagen. In the five 
patients they described the valves had been either sterilized or freeze-dried and all had acellular cusps ; one case ( 24 months) showed degenerative changes in collagen. These experiences are similar to the findings in the present study in which the cusps of all but one valve were acellular, the exception being a fresh valve transplanted after three days, and even in this case the appearances were almost certainly those of repopulation of donor cusp by host cells. Only four grafts examined at over three months had been grafted as fresh valves, and all but the case described had acellular cusps. These valves had been stored in nutrient medium for between 11 and 24 days. Comparing these four grafts with those of Lower et al., it would appear that there is a critical time within which grafting must be undertaken for donor cells to survive and that persistence of these cells within the fibrous framework in the dog at least, like stromal cells in human corneal grafts (Hanna and Irwin, 1962; Polack, Smelser, and Rose, 1964) and chondrocytes in cartilage grafts (Gibson, 1965), is possible for some considerable time and is not associated with a homograft response in the unvascularized graft. With the exception of this same (nine-month) case, cusp fibrous tissue in all older grafts showed variations from normal, and this and their acellularity contrasted with the apparently normal fibrous tissue of their sleeves which had been populated by host fibroblasts.

Although few untreated grafts are included in this series it is probably significant that all the grafts showing advanced fibrous tissue degeneration had been sterilized and all except the degenerate but unruptured case had also been freezedried. All the ruptures had been freeze-dried and, with one exception (at 24 months), had also been sterilized. This latter was the only rupture not showing collagen degeneration, which was so prominent a feature of the other late ruptured grafts. With such a small number of cases and with so much overlap of the two processes it is not possible to differentiate between any difference in effect of one or other method of treatment ; but it at least seems possible that the 'little denaturation' of tissue produced by $1 \%$ betapropiolactone (Rains et al., 1956) may be of vital significance in the survival of grafted valvular tissue. Pate (1954) classed freeze-dried grafts as those in which viability was not maintained but physical and chemical structure were not seriously altered. It may be that although these minor alterations do not affect grafts in other situations, they are important where such slender leaflets must withstand systemic systolic blood pressures.
Although it is possible that the cusp ruptures at about 17 months and after may reflect the survival time of fibrous and elastic tissue independent of treatment, the survival of Murray's original patient for eight years (Bigelow et al., 1964) and survival of early non-treated grafts performed at this hospital for up to four years (to date) argue against this.

It appears likely that there is also a difference in host reactions to fresh and treated material. In 1954 Pate stated that the freeze-dried aortic homograft in the dog was notably without rupture, haemorrhage, or thrombosis and said that microscopy indicated that the freeze-dried homograft was re-endothelialized faster, developed less scarring, and was, in general, more acceptable than other kinds of grafts. Work in conjunction with other authors was quoted in which removal of some of the protein from the graft by freezedrying and reconstitution had been demonstrated, and it was suggested that this reduced the antigenicity of this type of material. It was also suggested that alteration of the electrical potential in the dead graft might account for the lower incidence of thrombosis in comparison with fresh grafts. Thrombosis has not been a feature in the present series, most of which have been freezedried, and although the aortic sleeves have been covered by fibrin which becomes organized to form the intimal fibrous sheaths in all grafts surviving long enough, only three have shown a similar process extending on to the cusps and all three were non-freeze-dried. However, one patient (15 months) was in severe congestive heart failure and the other two had peripheral detachments batween the graft and host rings of sufficient magnitude to warrant re-operation. Under these conditions it may be that turbulence leading to fibrin deposition (Temple et al., 1964 ; Robicsek et al., 1962) on the cusps rather than alteration in surface electrical change was responsible for the extension of host fibrous sheath on to graft cusps. Lower and associates (1966) consider that freezedried or sterilized tissues do not provide an effective lattice work for host replacement, and the findings in the present series support this opinion. Further support may be offered by one of Bigelow's cases. Although it is not mentioned in the text, the oldest (14 months) of the three grafts examined histologically showed, in one of the illustrations, almost complete covering of the cusp sectioned by both lower and upper intimal fibrous sheaths. These valves had been taken aseptically and stored in saline penicillin at $4^{\circ} \mathrm{C}$. for up to five weeks. The host reaction is broadly similar to that of dogs to fresh mitral homografts 
(Berghuis et al., 1964 ; Van Vliet et al., 1965) but differs in being much slower, and whereas the canine mitral leaflets are completely covered by fibrous sheaths in a few months these sterilized and freeze-dried grafts are only partially sheathed even after two and a half years. While this may be a species difference or a reflection of the different methods of preparation of the grafts the site of grafting and the difference in valve function may also play a part. There has been no evidence in these human aortic valve transplants that seeding of cells from the bloodstream plays any part in organization or covering of the graft.

All fibrous sheaths have originated from organization of surface fibrin deposits overlying host tissue at each suture line. Cells within the graft sleeves have infiltrated from the reaction at the graft-host interface. The aortic annulus when prepared for grafting is a less vascular bed than that of the mitral ring, and this difference may play some part in the type and rate of response. It may also be possible that a difference in the type of movement of the atrioventricular and semilunar valves affects sheath extensions on to the aortic valve cusps. The aortic valve has a $90^{\circ}$ angle of movement occurring at the hinge (line of attachment) of the leaflets, and this may interfere with organization at this point. Tending to support this are observations on three human mitral valve homografts which were performed at this hospital and examined between six and 12 weeks after grafting. In these it was found that organizing granulation tissue similar to that described by Berghuis et al. and Van Vliet et al. in dogs extends from the annulus suture line down both surfaces of the transplanted leaflets.

Endothelium, with one exception (the single cusp graft at four-and-a-half months), was found on the grafts only in continuity with host endothelium. En face preparations have not been made, but at no stage was anything resembling endothelium seen on bare graft tissue. Enmeshed within, and on the surface of, isolated fibrin deposits large, rather flattened mononuclear cells were often found. These were found on grafts of all ages but at no stage resembled a true endothelial covering. The exception was the case in which a single cusp had been transplanted, and on the ventricular surface of this from the line of closure to the marginal border was an isolated organizing fibrous sheath partly covered by a single layer of flattened cells resembling endothelium. This was seen only in the region where the valve cusps touch in diastole. Lower et al. (1966), speaking of the human aortic homografts they examined also commented on the absence of endothelium. This is in contrast to the findings in the experimental animal by Stump, Jordan, De Bakey, and Halpert (1962) and O'Neal, Jordan, Rabin, De Bakey, and Halpert (1964).

The host cellular response to most of the grafts was that of mild chronic inflammation with gradual infiltration of the graft sleeve by poorly cellular organizing granulation tissue. The absence of evidence of a rejection phenomenon was hardly surprising since the transplants consisted of an acellular, dead, predominantly fibrous scaffolding. Davies et al. (1965), investigating a possible antibody response in patients a year after aortic valve homotransplantation, stated 'So faI as we can judge, there is so far no evidence of an immune reaction that is sufficiently severe to be clinically important'. The reason for the foreign body reaction in the lower sleeve of one graft and the heavy chronic inflammatory infiltrate in association with two ruptures is not apparent. No organisms were seen. Maurer, Gerulat, and Pinchuck (1962), working on the antigenicity of polypeptides in animals and man, found evidence from the cross-reactions of a response which was heterogeneous in the sense that not all individuals react against the same groupings in the complex polymers, and it may be that the cellular reactions in these three isolated cases represent a response to an antigenic stimulus of this type. Eosinophils were prominent in two of these cases, and Rogers, Converse, Taylor, and Campbell (1953) comment on a marked eosinophilia of up to eight times normal in full-thickness human skin homografts, stating that the infiltrate was maximal at the time the epithelium was sloughed. They also found an associated and comparable rise in circulating eosinophils.

Calcification occurred only in late grafts and it was notable that the deposits were in tissue not infiltrated by host cells.

My thanks are due to Mr. B. G. Barratt-Boyes and Dr. J. B. Lowe, respectively the surgeon and physician in charge of these cases, for permission to publish this material. Surgery was performed by Mr. Barratt-Boyes and Mr. D. S. Cole. Mr. R. Hart photographed the gross specimens.

Mr. J. Blazer made the illustration for Figure 1.

Mr. R. Patterson and Mr. J. Cole were in charge of the section cutting.

\section{ADDENDUM}

Since this report was submitted for publication two further valve ruptures have occurred. In each case the valve had been sterilized with betapropiolactone but not freeze-dried (BarrattBoyes, personal communication, 1966). 


\section{REFERENCES}

Austen, W. G., Corning, H. B., Moran, J. M., Sanders, C. A., and Scannell, J. G. (1966). Cardiac hemodynamics immediately following aortic valve surgery. J. thorac. cardiovasc. Surg. $51,468$.

Barratt-Boyes, B. G. (1964). Homograft aortic valve replacement in aortic incompetence and stenosis. Thorax, 19,131.

(1965). A method for preparing and inserting a homograft aortic valve. Brit. J. Surg., 52, 847.

- Lowe, J. B., Cole, D. S., and Kelly, D. T. (1965). Homograft valve replacement for aortic valve disease. Thorax, 20, 495.

Beall, A. C., Morris, G. C., Cooley, D. A., and De Bakey, M. E. (1961). Homotransplantation of the aortic valve. J. thorac. cardiovasc. Surg., 42, 497.

Berghuis, J., Rastelli, G. C., Van Vliet. P. D., Titus, J. L., Swan, H. J. C., and Ellis, F. H., Jr. (1964). Homotransplantation of the canine mitral valve. Circulation, 29, Suppl. 1, p. 47.

Best, P. V., and Heath, D. (1958). Pulmonary thrombosis in cyanotic congenital heart disease without pulmonary hypertension. J. Path. Bact., 75, 281.

Bigelow, W. G., Yao, J. K., Aldridge, H. E., Heimbecker, R. O., and Murray, G. D. W. (1964). Clinical homograft valve transplantation. J. thorac. cardiovasc. Surg., 48, 333.

Davies, H., Lessof, M. H., Roberts, C. I., and Ross, D. N. (1965). Homograft replacement of the aortic valve. Lancet, 1, 926.

Foster, J. H., Collins, H. A., Jacobs, J. K., and Scott, H. W., Jr. (1965). Long term follow-up of homografts used in the treatment of coarctation of the aorta. J. cardiovasc. Surg. (Torino), 6, 111

Gibson, T. (1965). Cartilage grafts. Brit. med. Bull., 21, 153.

Gross, R. E., Bill, A. H., Jr., and Peirce, E. C. (1949). Methods for preservation and transplantation of arterial grafts. Observations on arterial grafts in dogs. Report of transplantation of preserved arterial grafts in 9 human cases. Surg. Gynec. Obstet., 88, 689.

Hanna, C., and Irwin, E. S. (1962). Fate of cells in the corneal graft. Arch. Ophthal. (Chicago), 68, 810 .

Harp, R. A., Olson, 'C. L., and McGoon, D. C. (1963). Replacement of aortic valve in calves with homostatic homografts. Surg. Forum, 14, 249.

Heimbecker, R. O., Baird, R. J., Lajos, T. Z., Varga, A. T., and Greenwood, W. F. (1962). Homograft replacement of the human mitral valve: a preliminary report. Canad. med. Ass. J., 86, 805.

Hudson, R. E. B. (1966). Pathology of the human aortic valve homograft. Brit. Heart J., 28, 291.

Kelly, D. T. (1966). Myocardial function (studied using angiotensin) after aortic homograft valve replacement. N.Z. med. J., Suppl., 64, Dec., p. 68.

Kerwin, A. J., Lenkei, S. C., and Wilson, D. R. (1962). Aortic-valve homograft in the treatment of aortic insufficiency: report of nine cases, with one followed for six years. New Engl. J. Med., 266, 852 .

Lam, C. R., Aram, H. H., and Munnell, E. R. (1952). An experimental study of aortic valve homografts. Surg. Gynec. Obstet., 94, 129.

Lower, R. R., Pillsbury, R. C., Angell, W. W., and Kosek, J. C. (1966). Homograft heart valves. Circulation, 33, Suppl. 1, p. 135.

Magarey, F. R. (1949). On the mode of formation of Lambl's excrescences and their relation to chronic thickening of the mitral valve. J. Path. Bact., 61, 203.
Maurer, P. H., Gerulat, B. F., and Pinchuck, P. (1962). Antigenicity of polypeptides (poly alpha amino acids). VII. Studies in humans. J. exp. Med., 116, 521 .

McKenzie, M. B., Titus, J. L., Rastelli, G. C., Pappas, G., and Ellis, F. H., Jr. (1966). Replacement of the canine mitral valve with semilunar valves. J. thorac. cardiovasc. Surg., 51, 168.

Murray, G. (1956). Homologous aortic-valve-segment transplants as surgical treatment for aortic and mitral insufficiency. Angiolcgy, $7,466$.

- (1960). Aortic valve transplants. Ibid., 11, 99.

Nelson, T. G., and Cooley, D. A. (1964). Prosthetic replacement of the mitral or aortic valves. A preliminary report on 111 cases. Amer. J. Cardiol., 14, 148.

O’Neal, R. M., Jordan, G. L., Rabin, E. R., De Bakey, M. E., and Halpert, B. (1964). Cells grown on an isolated intravascular dacron hub. An electron microscopic study. Exp. molec. Path., $3,403$.

Pate, J. W. (1954). Transplantation of preserved non-viable tissues. In Presentation and Transplantation of Normal Tissues: $A$ Ciba Foundation Symposium, ed. G. E. W. Wolstenholme and M. P. Cameron, p. 60 . Churchill, London.

Polack, F. M., Smelser, G. K., and Rose, J. (1964). Long-term survival of isotopically labeled stromal and endothelial cells in corneal homografts. Amer. J. Ophthal., 57, 67.

Pritchard, G. R., Wright, J. S., and Johnston, J. B. (1966). The effect of beta-propiolactone on the tensile properties of human pericardium. J. thorac. cardiovasc. Surg., 52, 232.

Rains, A. J. H., Crawford, N., Sharpe, S. H., Shrewsbury, J. F. D. and Barson, G. J. (1956). Management of an artery-graft bank with special reference to sterilisation by beta-propiolactone. Lancet, 2, 830 .

Rich, A. R. (1948). A hitherto unrecognized tendency to the development of widespread pulmonary vascular obstruction in patients with congenital pulmonary stenosis (tetralogy of Fallot). Bull. Johns Hopk. Hosp., 82, 389.

Robicsek, F., Sanger, P. W., Taylor, F. H., and Robicsek, L. (1962). Transplantability of heart valves. Arch. Surg., 84, 141 .

Rogers, B. O., Converse, J. M., Taylor, A. C., and Campbell, R. M (1953). Eosinophile in human skin homografting. Proc. Soc exp. Biol. Med. (N.Y.), 82, 523 .

Ross, D. N. (1962). Homograft replacement of the aortic valve. Lancet, $2,487$.

Schwartz, C. J., and Mitchell, J. R. A. (1962). The relation between myocardial lesions and coronary artery disease. I. An unselected necropsy study. Brit. Heart J., $24,761$.

Sell, S., and Scully, R. E. (1965). Aging changes in the aortic and mitral valves. Histologic and histochemical studies, with observations on the pathogenesis of calcific aortic stenosis and calcification of the mitral annulus. Amer. J. Path., 46, 345.

Stump, M. M., Jordan, G. L., De Bakey, M. E., and Halpert, B. (1962). The endothelial lining of homografts and dacron prostheses in the canine aorta. Ibid., 40, 487.

(1963). Endothelium grown from circulating blood on isolated intravascular dacron hub. Ibid., 43, 361.

Temple, L. J., Serafin, R., Calvert, N. G., and Drabble, J. M. (1964). Principles of fluid mechanics applied to some situations in the human circulation and particularly to the testing of valves in a pulse duplicator. Thorax, 19, 261.

V'an Vliet, P. D., Titus, J. L., Berghuis, J., and Ellis, F. H., Jr. (1965). Morphologic features of homotransplanted canine mitral valve s. J. thorac. cardiovasc. Surg., 49, 504. 